\title{
Natural Gas Accumulation Characteristics in the Linxing Area, Ordos Basin, NW China: Revealed from the Integrated Study of Fluid Inclusions and Basin Modeling
}

\author{
Yong Shu $\mathbb{D}^{1,2}$ Shuxun Sang $\mathbb{D}^{1,2}$ Yuxiang Lin, ${ }^{3}$ and Huiming Zheng ${ }^{4}$ \\ ${ }^{1}$ Key Laboratory of Coalbed Methane Resources and Reservoir Formation Process, Ministry of Education, China University of Mining \\ and Technology, Xuzhou 221116, China \\ ${ }^{2}$ School of Resources and Geosciences, China University of Mining and Technology, Xuzhou 221116, China \\ ${ }^{3}$ Shandong Provincial Key Laboratory of Depositional Mineralization \& Sedimentary Minerals, College of Earth Science \\ and Engineering, Shandong University of Science and Technology, Qingdao 266590, China \\ ${ }^{4}$ Shandong Provincial Lunan Geo-engineering Exploration Instituts, Jining 272100, China \\ Correspondence should be addressed to Shuxun Sang; shxsang@cumt.edu.cn
}

Received 11 November 2019; Revised 24 July 2020; Accepted 31 July 2020; Published 25 August 2020

Academic Editor: Henrik Drake

Copyright (C) 2020 Yong Shu et al. This is an open access article distributed under the Creative Commons Attribution License, which permits unrestricted use, distribution, and reproduction in any medium, provided the original work is properly cited.

\begin{abstract}
The Linxing area is located in the north of the eastern margin of the Ordos Basin, which has great resource potential for tight gas. In this paper, fluid inclusion analysis and basin modeling are the main means to clarify the gas accumulation mechanism of the Upper Paleozoic in the Linxing area. Petrographic analysis shows that fluid inclusions can be classified into 5 types: aqueous inclusions, hydrocarbon-bearing aqueous inclusions, hydrocarbon inclusions, crystal-bearing aqueous inclusions, and aqueous-carbonic inclusions. According to the statistical analysis of homogenization temperature and salinity of fluid inclusions, combined with the burial-thermal evolution, the study area was divided into 3 areas: the inner-magma baking area, the middle-anomal thermal area, and the outer-normal thermal area. The gas accumulation characteristics are differences among the 3 areas, the closer to Zijinshan magmatic pluton, the earlier gas accumulation period; and the vertical gas accumulation in the inner-magma baking area and the middle-anomal thermal area was not a slow and gradual process from bottom to top. The period from the Middle Jurassic to the Early Cretaceous is the key period for rapid pressure accumulation in the Upper Paleozoic reservoirs, which is consistent with the period of natural gas accumulation. The area near the Zijinshan magmatic pluton was the high fluid potential area during the gas accumulation period, which indicates that natural gas and other fluids migrated from Zijinshan magmatic pluton to the surrounding area. It is concluded that in the Linxing area, the Zijinshan magmatic pluton had a significant impact on natural gas accumulation, and the natural gas accumulation model under the control of magmatic thermal-tectonic effect was proposed.
\end{abstract}

\section{Introduction}

The study of hydrocarbon accumulation characteristics is an important part of oil and gas geology research, which can indicate the formation and enrichment of oil and gas, and is of great significance for the exploration and development of oil and gas resources [1-4]. Unconventional oil and gas resources (such as tight gas) account for a growing proportion of global energy consumption, and its accumulation model is more complicated than conventional oil and gas
[5-7]. In 2017, China's tight gas production was $343 \times 10^{8}$ $\mathrm{m}^{3}$, mainly from the Sichuan Basin and the Ordos Basin [8]. The tight gas resources in the Ordos Basin are $14.4 \times$ $10^{12} \mathrm{~m}^{3}$, accounting for $59 \%$ of the total tight gas resources in China [9]. Several large-scale tight gas fields have been found in the Ordos Basin, such as the Sulige gas field, the Mizhi gas field, and the Shenmu gas field, which are important tight gas industrial bases in China $[9,10]$. The Linxing area is a favorable area for the exploration and development of unconventional natural gas from coal measures in the 
Ordos Basin. The development of coalbed methane in the Linxing area has formed a certain industrial scale, and tight gas has become the focus of next exploration and development $[11,12]$. In particular, the maturities of the source rocks in the Linxing area are higher than that in the adjacent areas (the vitrinite reflectance of the source rocks is generally greater than $1.0 \%$ ), and the fractures in the coal and tight sandstones are developed [12-14], so the prospect for exploration and development of tight gas is generally promising.

Previous studies have been carried out on the process of natural gas accumulation in the Linxing area, such as hydrocarbon generation-expulsion simulation to determine the accumulation period $[13,15]$, but it is only a general accumulation period, and cannot explain whether natural gas is ${ }^{1}$ multistage accumulation. Fluid inclusions are paleo-fluids trapped in the mineral lattice defects, which represent the original physical and chemical characteristics of the paleofluids in its formation period, and act as effective means to determine the hydrocarbon accumulation characteristics $[1,16-21]$. The predecessors used fluid inclusion analysis to conclude that the gas accumulation in the Upper Paleozoic in the Ordos Basin was mostly continuous accumulation of 2-6 periods [22-25]. However, the previous research scopes are often large (the whole gas field), resulting in low research accuracy, and it is possible to neglect the different accumulation characteristics of different locations in the same gas field. Under the dual influence of the Yanshanian tectonic-thermal event and the thermaltectonic effect caused by Zijinshan magmatic pluton, the process of gas accumulation in the Linxing area is more complex. Previous studies are limited to the description of current phenomena, such as the vitrinite reflectance (Ro) of source rocks around Zijinshan magmatic pluton decreases annularly $[12-15,26]$, and have not clarified the specific mechanism controlling gas accumulation.

In this paper, fluid inclusion analysis and basin modeling are used as the main research methods. Compared with previous studies, this paper is not limited to the overall general understanding of the gas accumulation characteristics in the study area but focuses on the difference of gas accumulation characteristics in different locations of the study area under the influence of Zijinshan magmatic pluton. Specifically, first of all, according to the microthermometry characteristics of fluid inclusions, combined with burial-thermal evolution and hydrocarbon generation-expulsion simulation of multiple wells, reliable gas accumulation periods and their regional differences are obtained. Secondly, through the trapping pressure simulation of fluid inclusion, the evolution of reservoir pressure and paleo-fluid potential is restored, and then, the gas accumulation process and characteristics under the influence of Zijinshan magmatic pluton are summarized in detail. Finally, the gas accumulation model under the influence of Zijinshan magmatic pluton is established to provide reference for the natural gas development in the study area.

\section{Geological Setting}

The Linxing area is located in the north of the Jinxi fold belt in the Ordos Basin (Figure 1). The sedimentary environment of the Upper Paleozoic from the bottom to the top gradually evolved from the marine facies to the marine-terrigenous facies and continental facies. According to drilling and outcrop observation, the Upper Paleozoic from the bottom to the top is as follows: Benxi Formation $\left(\mathrm{C}_{2} \mathrm{~b}\right)$ in Upper Carboniferous, Taiyuan Formation $\left(\mathrm{P}_{1} \mathrm{t}\right)$ and Shanxi Formation $\left(\mathrm{P}_{1} \mathrm{~s}\right)$ in Lower Permian, Shihezi Formation $\left(\mathrm{P}_{2} \mathrm{~h}\right)$ in Middle Permian, and Shiqianfeng Formation $\left(\mathrm{P}_{3} \mathrm{~s}\right)$ in Upper Permian (Figures 1 and 2). The Upper Paleozoic is unconformity with the underlying Ordovician Majiagou Formation and the overlying Triassic strata.

Located in the south-central part of the study area, the Zijinshan magmatic pluton mainly intruded into the Ordovician, with an outcrop area of approximately $23.3 \mathrm{~km}^{2}$ (Figure 1) [14]. Through SHRIMP dating and isotope analysis, scholars believe that the formation period of Zijinshan magmatic pluton is mainly in the Jurassic-Cretaceous (160 Ma-120 Ma), and some samples are aged from $195 \mathrm{Ma}$ to $160 \mathrm{Ma}$ [27-34]. The formation of Zijinshan magmatic pluton is closely related to strong tectonic thermal events and frequent volcanic activities in the eastern part of North China Plate during the Yanshanian period [30, 32, 34].

The source rocks are mainly the coal measure source rocks of marine-terrigenous facies in $\mathrm{C}_{2} \mathrm{~b}, \mathrm{P}_{1} \mathrm{t}$, and $\mathrm{P}_{1} \mathrm{~s}$, including coal and dark mudstones. The cumulative thickness of the coal seam is $15 \mathrm{~m}-24 \mathrm{~m}$, with high maturity and stable distribution [12]. Multiple sets of sandstone reservoirs and mudstone caprocks were developed in the Upper Paleozoic, among which the fluvial sandstone reservoirs in $\mathrm{P}_{1} \mathrm{~s}$ and $\mathrm{P}_{2} \mathrm{x}$ are stable thickness and widely gas bearing [13]. The overlying thick mudstone of $\mathrm{P}_{2} \mathrm{~s}$ and $\mathrm{P}_{3} \mathrm{~s}$ serve as regional caprocks, providing good preservation conditions for gas reservoirs.

\section{Samples and Methods}

3.1. Samples and Instruments. In this study, fluid inclusions samples were collected from 65 core samples of tight reservoirs from 11 wells. According to the methods for rock thin section preparation [35] and measurement of homogenization temperature and salinity of inclusions in sedimentary rock [36], the samples were prepared as 1-mm-thick double-polished thin section for microthermometric measurement.

The Axio Scope A1 microscope and Axioskop 40 Pol microscope are used to observe and analyze fluorescence and petrographic characteristics of fluid inclusions. The Linkam THMSG 600 heating/cooling stage (temperature range: $-196^{\circ} \mathrm{C}$ to $600^{\circ} \mathrm{C}$ ) was used to bring the fluid inclusions to a uniform state, and the measurement error of the homogenization temperatures of fluid inclusions was less than $0.1^{\circ} \mathrm{C}$. The gas-liquid ratios of hydrocarbon inclusions were measured by Confocal Laser Scanning Microscopy. The gasliquid ratios of aqueous inclusions and hydrocarbon-bearing aqueous inclusions were calculated by the method proposed by Zhou et al. [37], using petrographic microscopy and fluorescent microscopy, obtain a series of two-dimensional images of single fluid inclusion. Details of the approaches, methods, and software used are given by Zhou et al. [37]. 


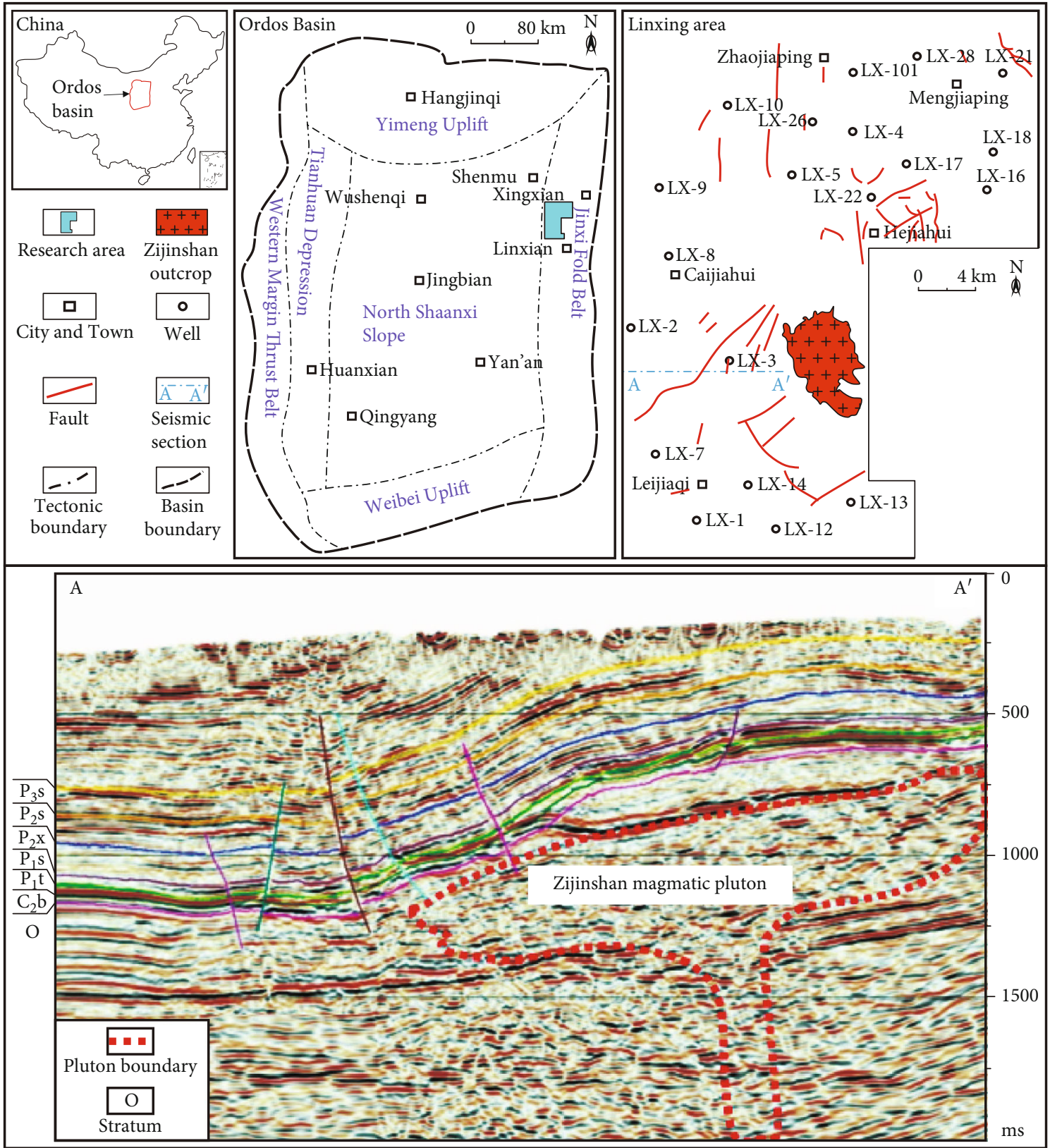

FIGURE 1: Comprehensive geological map of the Linxing area (the seismic section is cited from [14]).

\subsection{Methods}

3.2.1. Petrography. The fluid filling time during diagenesis could be established through the analysis of the textural relationships between host minerals and fluid inclusions, and fluorescence and phase characters of fluid inclusions. The hydrocarbon inclusions, which were irradiated by ultraviolet light, produced fluorescence colors in the visible light range (wavelength of $400 \mathrm{~nm}-700 \mathrm{~nm}$ ), while the hydrocarbonbearing aqueous inclusions and aqueous inclusions exhibited no fluorescence [38]. If the fluid inclusions were trapped from a uniform state, after the temperature decreased, associated with the fluid composition and density, the single liquid phase, single vapor phase, and vapor-liquid phase may be formed.
3.2.2. Microthermometry. Microthermometry includes the measurement of homogenization temperature and freezing temperature of fluid inclusions. The homogenization temperature of nonsingle-phase fluid inclusions is the temperature when the inclusion phases transform into a single uniform phase. The freezing temperature is the temperature when the frozen inclusion is heated and the last ice disappears, which is related to the salinity of fluid. The salinity of aqueous inclusions was calculated using a freezing temperature [39].

It should be noted that fluid inclusions of the same type and phase usually have similar homogenization temperature, salinity, gas-liquid ratio, and other characters. The homogenization temperature of hydrocarbon inclusions is slightly lower than its coeval aqueous inclusions, and aqueous 


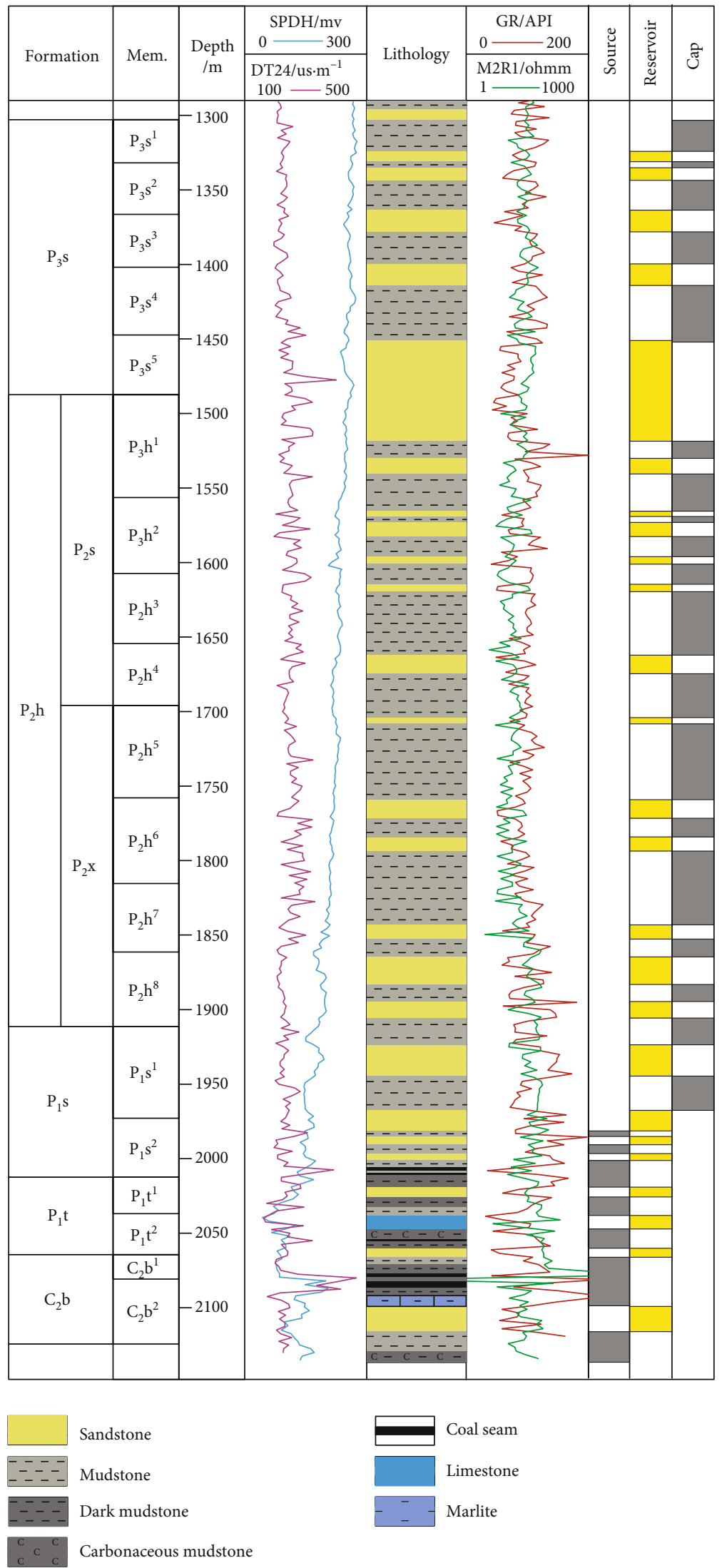

FIgURE 2: Lithological and stratigraphic system in the Linxing area. 
inclusions can better reflect the real stratum temperature $[22,24,38]$.

3.2.3. Simulation of Burial-Thermal Evolution and Hydrocarbon Generation-Expulsion. The PetroMod 2012 basin modeling software from Schlumberger ltd (http://www .software.slb.com/products/petromod) was used to simulate the burial-thermal evolution and hydrocarbon generationexpulsion.

The required data for reconstruction of burial-thermal includes stratigraphic age, stratigraphic lithology, denudation thickness, paleo-heat flow, and paleo-water depth. The stratigraphic age and stratigraphic lithology reference to Stratigraphic Chronology of Ordos Basin (Changqing Oilfield). Through the logging data analysis, the denudation thickness was restored by using the mudstone interval transit time and depth model proposed by Liu et al. [40]. The initial paleo-heat flow refers to the study of the paleo-heat flow in the northeastern Ordos Basin [41-43] (Figure S1). Based on previous studies of sedimentary facies and paleo-water depth of the Ordos Basin [44-46], the paleo-water depth evolution is set as shown in Table S1.

Based on the reconstructed burial-thermal evolution, combined with the total organic carbon (TOC) and kerogen pyrolysis analysis data of coal samples (Table S2), the Tissot in Waples [47] TIII Crack kinetic model in PetroMod 1D software was used to simulate the hydrocarbon generationexpulsion of source rock.

3.2.4. Determination of Gas Accumulation Periods. According to the burial-thermal evolution, the age information of aqueous inclusions can be ascertained based on its homogenization temperatures. Then, the formation time of the coeval hydrocarbon inclusions can be ascertained. Finally, the charging time of the natural gas can be determined $[48,49]$.

3.2.5. Trapping Pressure Simulation. Using PVTSIM 20 fluid simulation software (http://www.calsep.com/services/ multiphase-meter-customized-pvt-software.html), input fluid inclusions' homogenization temperature, gas-liquid ratio, the assumed components of hydrocarbon-bearing aqueous inclusions based on the current gas reservoir components, and the assumed components of hydrocarbon inclusions, then the pressure-temperature (P-T) phase diagrams and isochores of the hydrocarbon inclusions can be obtained. Details of the approaches, methods, and software used are given by Aplin et al. [16, 17], Mi et al. [50], and Zhang et al. [51].

3.2.6. Paleo-Fluid Potential Calculation. As functions of fluid pressure, density, elevation, temperature, etc., the fluid potential and the fluid potential gradient are effective means for portraying the trend of fluid migration in petroleum geology. On the basis of pressure recovery, combined with the burial-thermal evolution, the fluid potential distribution during the main accumulation period was recovered using the Hubbert fluid potential equation [52]. Equation (1) is the Hubbert fluid potential equation:

$$
\Phi=g z+\int_{0}^{p} \frac{1}{\rho} d p+\frac{1}{2} v^{2}
$$

where $\Phi$ is the fluid potential, $\mathrm{m}^{2} / \mathrm{s}^{2} ; g$ is the gravitational acceleration, $\mathrm{m} / \mathrm{s}^{2} ; z$ is the elevation of the calculated position relative to the datum plane (usually the ground), $m ; p$ is the fluid pressure, which is approximately equal to the trapping pressure of the fluid inclusions, $\mathrm{Pa} ; \rho$ is the fluid density, which is approximately equal to the density of the fluids inclusions [53], $\mathrm{kg} / \mathrm{m}^{3}$; and $v$ is the fluid velocity, $\mathrm{m} / \mathrm{s}$.

Considering that the deep underground fluid migration velocity is very low, the value of $v$ is approximately 0 . In addition, water, oil, and other liquid molecules are very small and almost incompressible, which means the density can be approximated as a fixed value. Therefore, equation (1) can be simplified to:

$$
\Phi=g z+\frac{P}{\rho} .
$$

The simulation of fluid pressure and calculation of density are based on hydrocarbon-bearing aqueous inclusions and aqueous inclusions, and the fluid potential mainly indicates the migration of formation water. However, the migration of oil and gas fluids is highly consistent with the migration of formation water $[54,55]$, and the results have implications for identifying hydrocarbon migration and accumulation.

\section{Results}

4.1. Petrographic Characteristics. The fluid inclusions of Upper Paleozoic reservoirs in Linxing area are in different shapes, most of which are round and elliptical, while a few of them are square, rectangular, and irregular (Figure 3). Fluid inclusions are mainly distributed in the secondary fractures and overgrowth of quartz particles, with regular banded distribution along with the fractures.

In the study area, 5 types of inclusions, such as aqueous inclusions, hydrocarbon-bearing aqueous inclusions, hydrocarbon inclusions, crystal-bearing aqueous inclusions, and aqueous-carbonic inclusions, were found (Figure 3). Fluid inclusions are usually two-phase (vapor + liquid) at room temperature $\left(25^{\circ} \mathrm{C}\right)$, except for the crystal-bearing aqueous inclusions, and colorless, yellow, brown, gray, and black under transmission light.

The aqueous inclusions have the highest abundances in the study area and are small in size $(3 \mu \mathrm{m}-12 \mu \mathrm{m})$. Usually, the volume of the liquid phase is larger than that of the vapor phase, and the gas-liquid ratio ranges from $3 \%$ to $10 \%$. They are colorless and light brown under transmission light (Figure 3(a)).

The hydrocarbon-bearing aqueous inclusions are generally $3 \mu \mathrm{m}-12 \mu \mathrm{m}$ in diameter. The volume of the liquid phase is usually larger than that of the vapor phase, and the gasliquid ratio (5\%-20\%) is higher than that of aqueous inclusions. Generally, it is light brown and brown under transmission light, and a few inclusions show weak blue-white fluorescence under ultraviolet light (Figures 3(b) and 3(c)). 


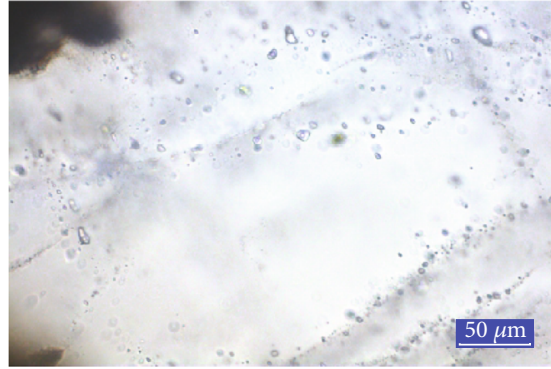

LX-21, $\mathrm{P}_{2} \mathrm{~s}, 1465.35 \mathrm{~m}$

(a)

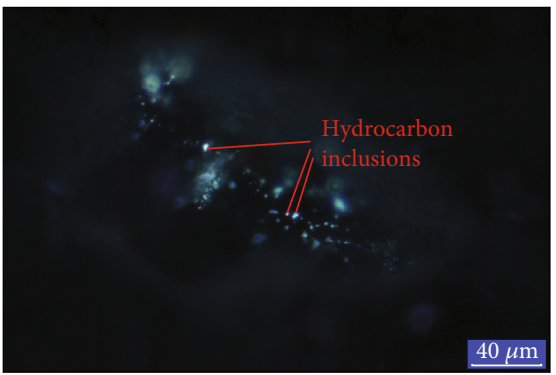

LX-17, $\mathrm{P}_{2} \mathrm{~s}, 1451.93 \mathrm{~m}$

(d)

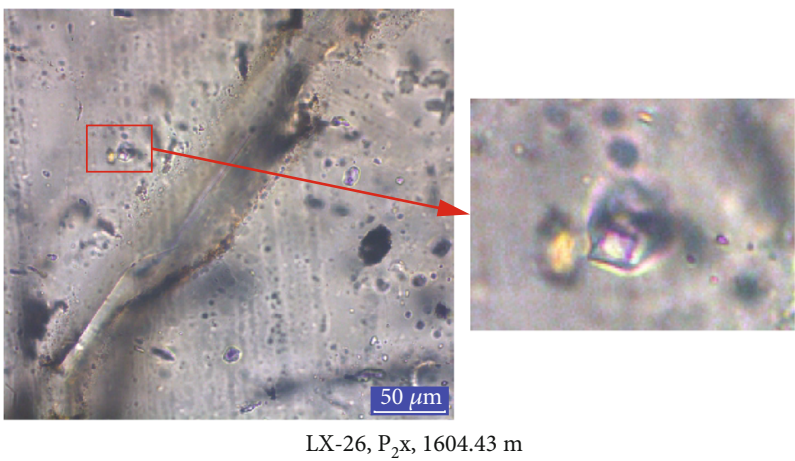

(g)
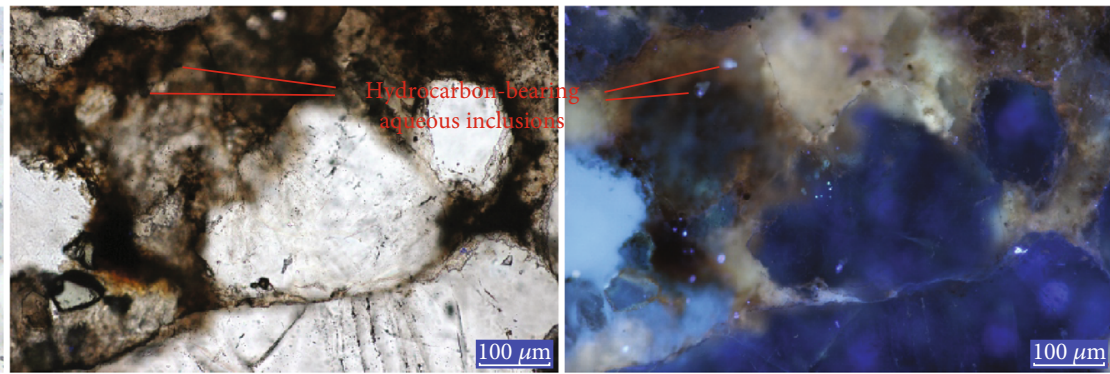

LX-17, $\mathrm{P}_{1} \mathrm{t}, 1852.86 \mathrm{~m}$

(b)

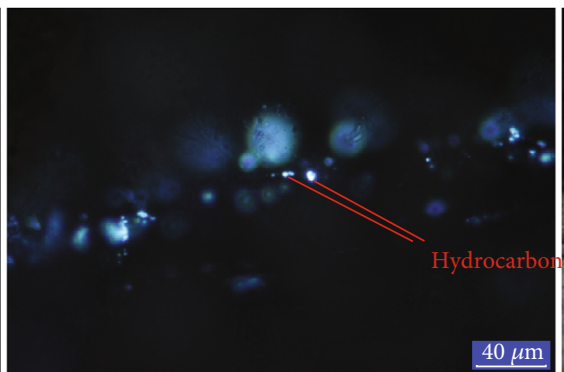

LX-17, $\mathrm{P}_{1} \mathrm{t}, 1892.10 \mathrm{~m}$

(e)

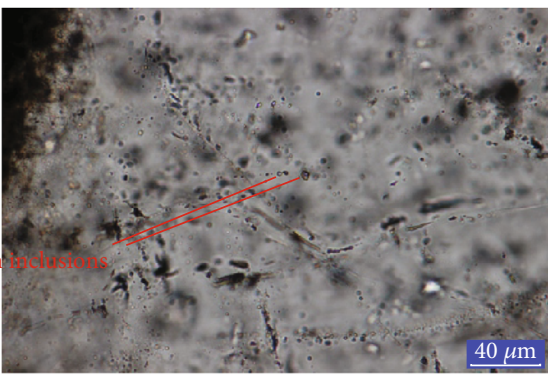

(f)

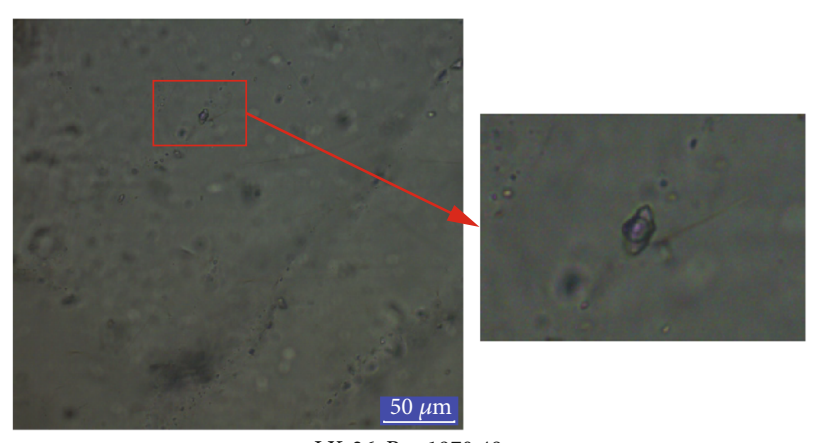

LX-26, $\mathrm{P}_{1} \mathrm{t}, 1970.48 \mathrm{~m}$

(h)

Figure 3: Photomicrograph of fluid inclusions in the Linxing area.

The hydrocarbon inclusions are relatively large $(5 \mu \mathrm{m}$ $18 \mu \mathrm{m})$ with the gas-liquid ratio of $10 \%$ to $60 \%$. They are mainly light brown and brown under transmission light. Hydrocarbon inclusions have the property that the fluorescence under ultraviolet light changes from brown to yellow to white to blue as the increasing maturity of organic matter [56-58]). Most hydrocarbon inclusions in the study area show bright yellow or blue-white fluorescence, indicating that their organic matter has a certain maturity (Figures 3(d)-3(f)).

The crystal-bearing aqueous inclusions, ranging in size from $3 \mu \mathrm{m}$ to $12 \mu \mathrm{m}$, contain the crystals formed by cooling in aqueous containing a solute that is supersaturated. They are three-phases (vapor + liquid + solid) at room temperature with the gas-liquid ratio of $5 \%-10 \%$. The liquid phase is colorless and light brown under transmission light, and the crystals are colorless and transparent cubes (Figure 3(g)).

The aqueous-carbonic inclusions are composed of gaseous $\mathrm{CO}_{2}$, liquid $\mathrm{CO}_{2}$, and aqueous at room temperature, and the boundaries are obvious. Its diameter is generally between $10 \mu \mathrm{m}$ and $15 \mu \mathrm{m}$, the gas-liquid ratio ranges from $10 \%$ to $20 \%$, and it is light brown and brown under transmitted light (Figure 3(h)).

Under the influence of tectonic stress, differential compaction and abnormal high pressure, the Upper Paleozoic reservoir in Ordos Basin experienced multistage of microfracturing $[2,59,60]$. Meanwhile, organic acids generated in the hydrocarbon generation process of coal measure source rocks can dissolve unstable minerals such as pyroclasts and feldspars, and generate large amounts of $\mathrm{Si}^{4+}$, providing material sources for the formation of quartz overgrowth [61]. Therefore, it is a common way to divide the phases of fluid inclusions in Ordos Basin based on whether the secondary fractures with fluid inclusions cut through quartz particles and its overgrowth [62-65]. According to the results of cathode luminescence scan (Figure S2), the development degree of quartz overgrowth is generally low, most of which are quartz overgrowth with thin local distribution, and only a few of quartz particles are completely surrounded by overgrowth. Based on the above 


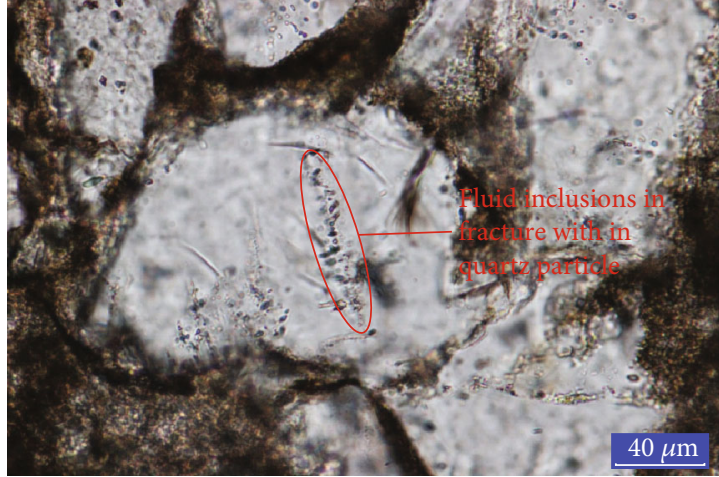

LX-18, $\mathrm{P}_{2} \mathrm{X}, 1767.49 \mathrm{~m}$

(a)

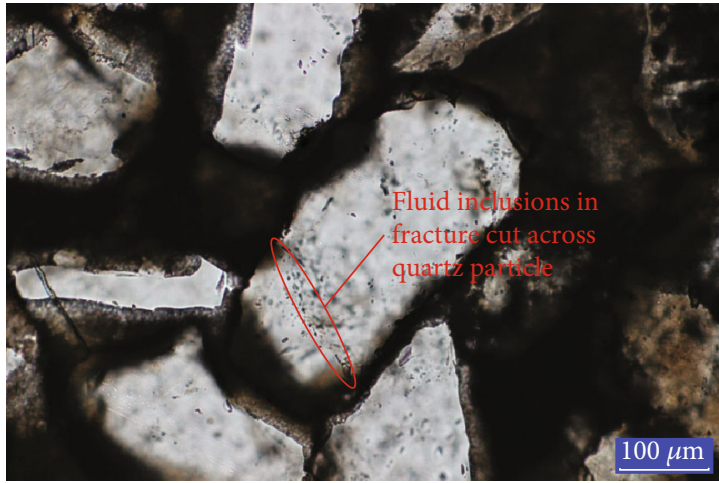

LX-17, $\mathrm{P}_{2} \mathrm{~s}, 1453.12 \mathrm{~m}$

(c)

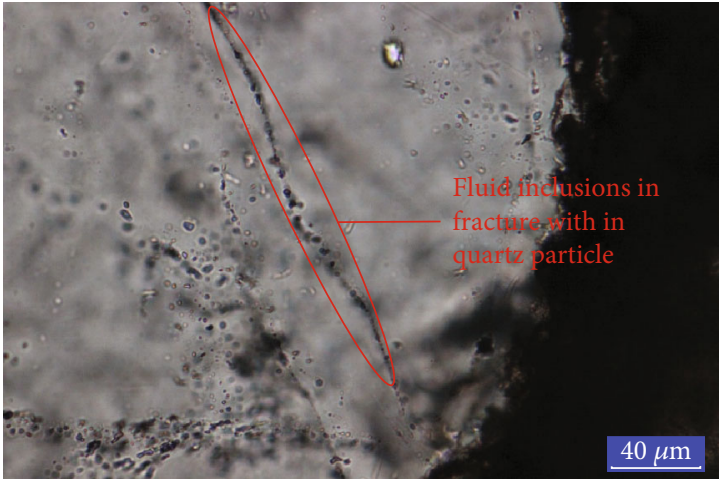

LX-18, $\mathrm{P}_{2} \mathrm{x}, 1760.61 \mathrm{~m}$

(b)

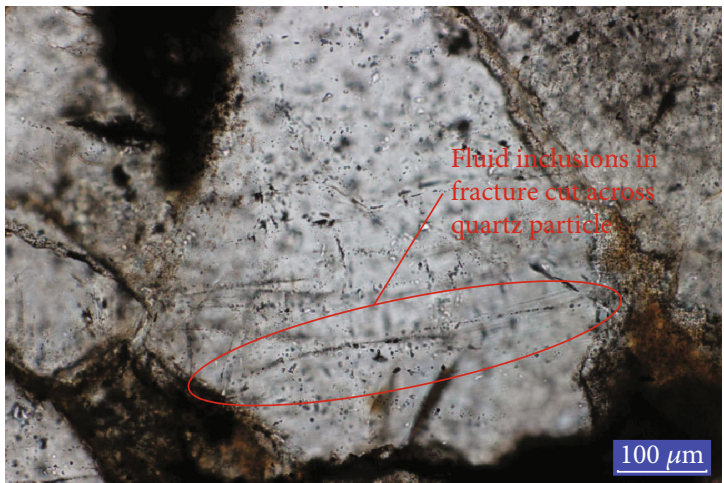

LX-17, $\mathrm{P}_{1} \mathrm{t}, 1892.10 \mathrm{~m}$

(d)

Figure 4: Petrographic photographs of fluid inclusions in the Linxing area.

analysis, fluid inclusions in Linxing area were divided into 2 phases according to the occurrence of quartz particle secondary fractures. Early fluid inclusions were distributed in the first stage (early) fractures which have a limited extension distance and generally within the quartz particles (Figure S3; Figures 4(a) and 4(b)). Later fluid inclusions were trapped by second stage (later) fractures that have cut across the quartz particles and its overgrowth (Figure S3; Figures 4(c) and 4(d)). In the early fluid inclusions, there are only a few bright yellow fluorescent hydrocarbon inclusions, and in the later fluid inclusions, the proportion of hydrocarbon inclusions increases significantly (Figure S3).

\subsection{Microthermometry Characteristics. The homogenization} temperature of aqueous inclusions associated with hydrocarbon inclusions is closest to the real stratum temperature at the time of hydrocarbon charging. Therefore, it is preferable to select such inclusions to study the history of gas charging. According to the homogenization temperature statistics of samples (Table 1), it is considered that the distribution characteristics of homogenization temperature among different wells are quite different and can be divided into 3 groups. Group 1, including LX-12 well, LX-17 well, LX-18 well, and LX-22 well, has homogenization temperature distribution of $70^{\circ} \mathrm{C}-160^{\circ} \mathrm{C}$. Group 2, including LX-1 well, LX-2 well, and LX-4 well, has homogenization temperature distribution of $80^{\circ} \mathrm{C}-200^{\circ} \mathrm{C}$. Group 3, including LX-21 well, LX-26 well,
LX-28 well, and LX-101 well, has homogenization temperature distribution of $60^{\circ} \mathrm{C}-150^{\circ} \mathrm{C}$.

The isoline maps of average homogenization temperature and salinity were drawn, and the obvious regularity distribution was found. As shown in Figure 5(a), the homogenization temperatures of LX-1, LX-2, and LX-4 wells are higher than that of other wells, and decreases to both sides. The salinity distribution shows a "northwest to southeast decline" distribution pattern (Figure 5(b)). The above research shows that the fluid in the reservoir has obvious heterogeneity and regularity difference during the period of natural gas charging.

Based on the above analysis results, the homogenization temperatures and salinity of fluid inclusions are further analyzed. The study area is divided into 3 zones from the Zijinshan magmatic pluton outward: inner zone, middle zone, and outer zone, which correspond to 3 types of homogenization temperature and salinity distribution characteristics, respectively (Figure 6).

In the inner zone (Group 1), the homogenization temperatures are generally low $\left(70^{\circ} \mathrm{C}-160^{\circ} \mathrm{C}\right)$, and there are early and later fluid inclusions, but the number of later fluid inclusions is small and their distribution is not obvious. The salinity ranges from $2 \%$ to $22 \%$ and increases with the increase of homogenization temperature.

In the middle zone (Group 2), the homogenization temperatures are generally higher $\left(80^{\circ} \mathrm{C}-200^{\circ} \mathrm{C}\right)$, and there 
TABLE 1: Homogenization temperature statistics table of fluid inclusions in the Linxing area.

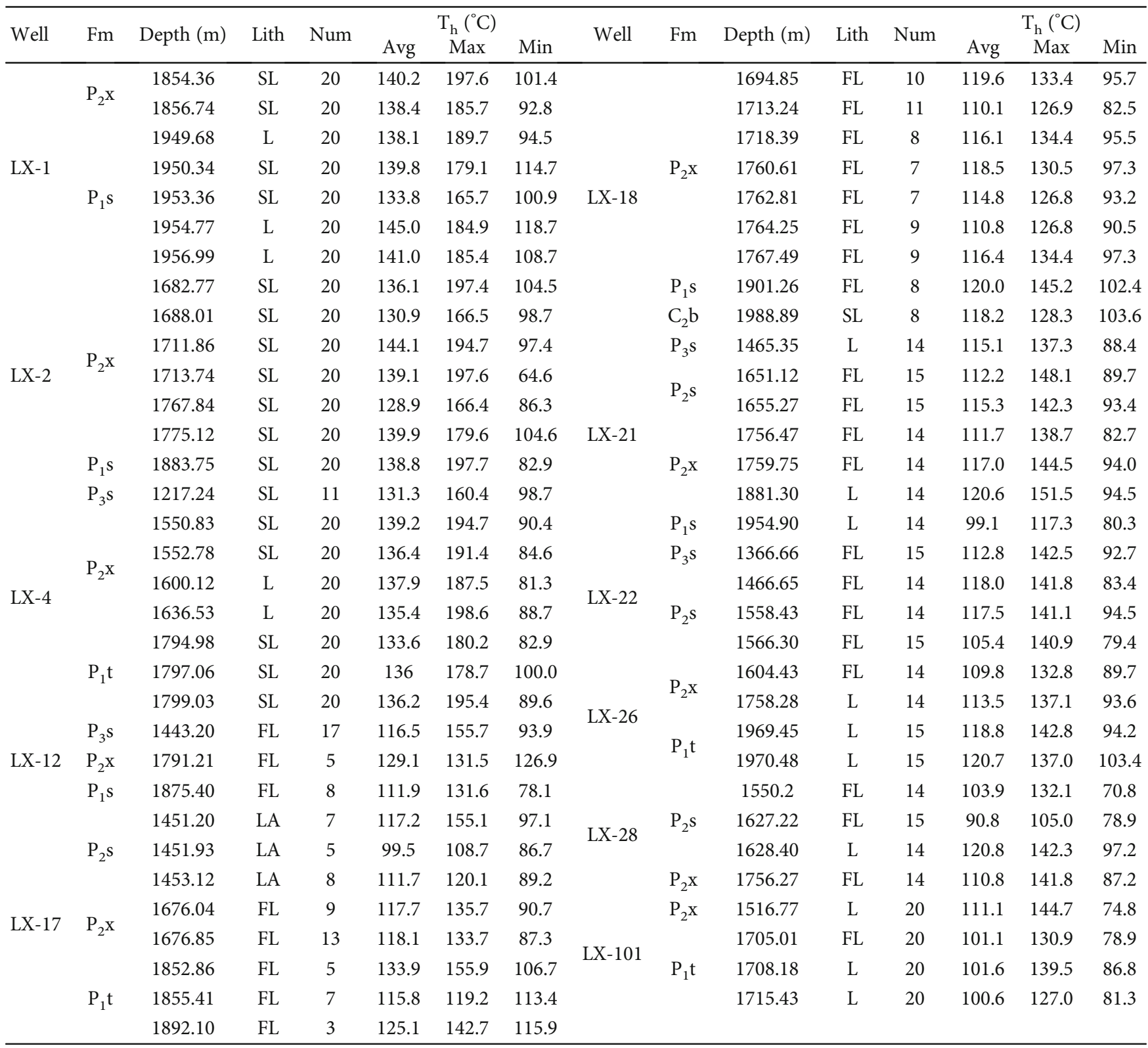

Fm: formation; Lith: lithology; Num: number; $\mathrm{T}_{\mathrm{h}}$ : homogenization temperature; L: litharenite; SL: sublitharenite; FL: feldspathic litharenite; LA: lithic arkose.

are early and later fluid inclusions. The salinity ranges from $4 \%$ to $23 \%$ and increases with the increase of homogenization temperature.

In the outer zone (Group 3), the homogenization temperatures are generally low $\left(60^{\circ} \mathrm{C}-150^{\circ} \mathrm{C}\right)$, and there are early and later fluid inclusions. The salinity ranges from $2 \%$ to $22 \%$. The data distribution is discrete and the regularity is poor.

\subsection{Burial-Thermal Evolution and Hydrocarbon Generation- Expulsion}

4.3.1. Burial-Thermal Evolution. There are 4 main unconformities in the Ordos basin: unconformities between TriassicJurassic, Jurassic Yan'an Formation-Zhiluo Formation, Jurassic-Cretaceous, and Cretaceous-Quaternary, indicating that the basin has experienced at least 4 major uplifting and denudations $[66,67]$. In the study area, for the first 3 uplift denuded thickness, the unconformity surfaces have been denuded due to the large uplift since the Late Cretaceous, which makes it difficult to recover. According to previous studies, the total denuded thickness of the first 3 denudations in the northeastern Ordos Basin is only about $300 \mathrm{~m}$, which has little effect on the recovery of sedimentary burial evolution [68]. Therefore, the first 3 denudations thickness recovered by Chen et al. [68] is used as the fixed value, which is $80 \mathrm{~m}, 60 \mathrm{~m}$, and $200 \mathrm{~m}$ in turn. The denuded thickness is caused by uplift, since the Late Cretaceous is mainly determined by the interval transit time through the study of mudstone compaction trend [40]. The results show that the denuded thickness since the Late Cretaceous ranged from 


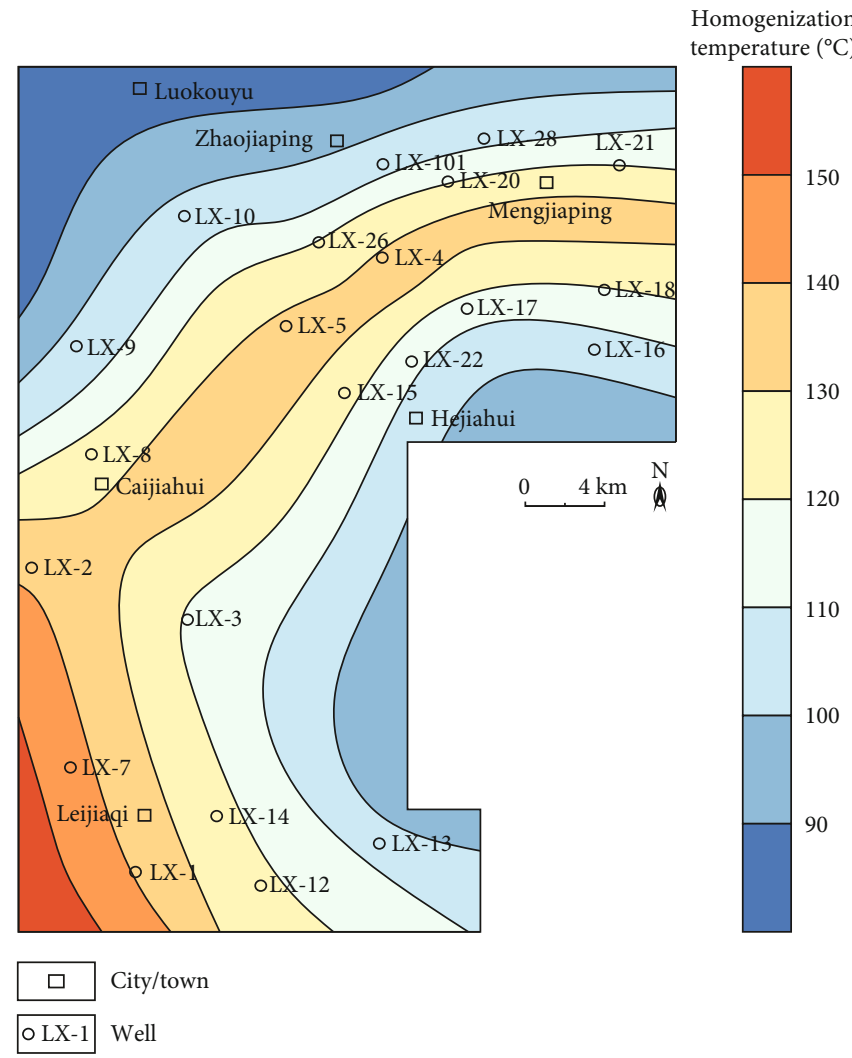

(a)

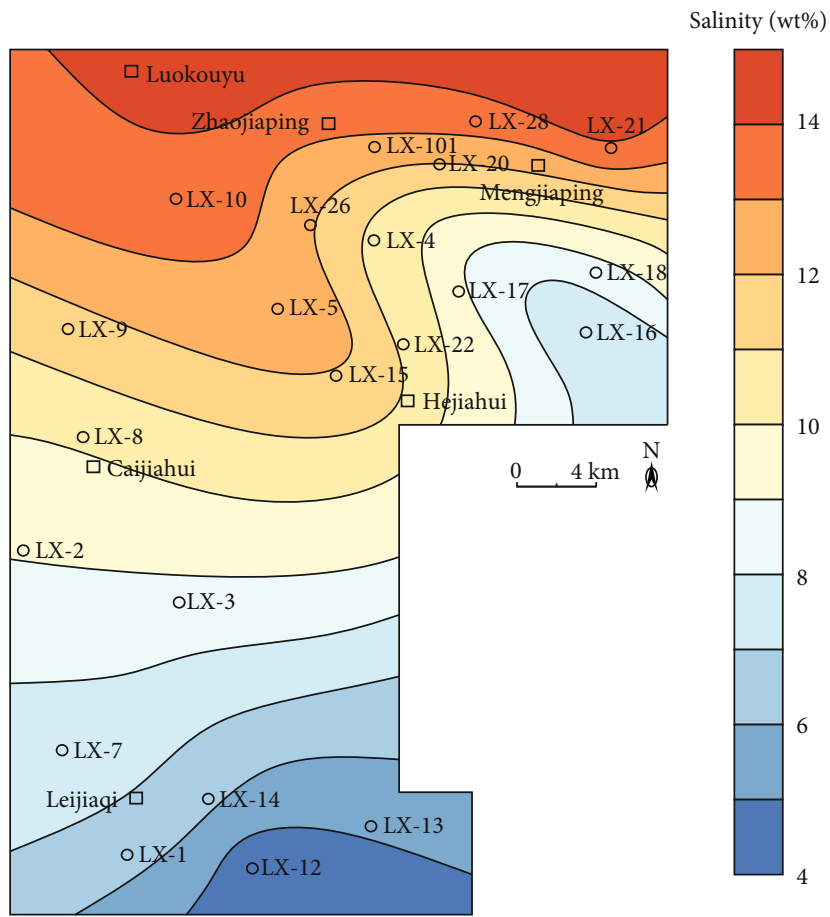

$\square$ City/town

O LX-1 Well

(b)

Figure 5: Isogram of homogeneous temperature and salinity of fluid inclusions in the Linxing area. 

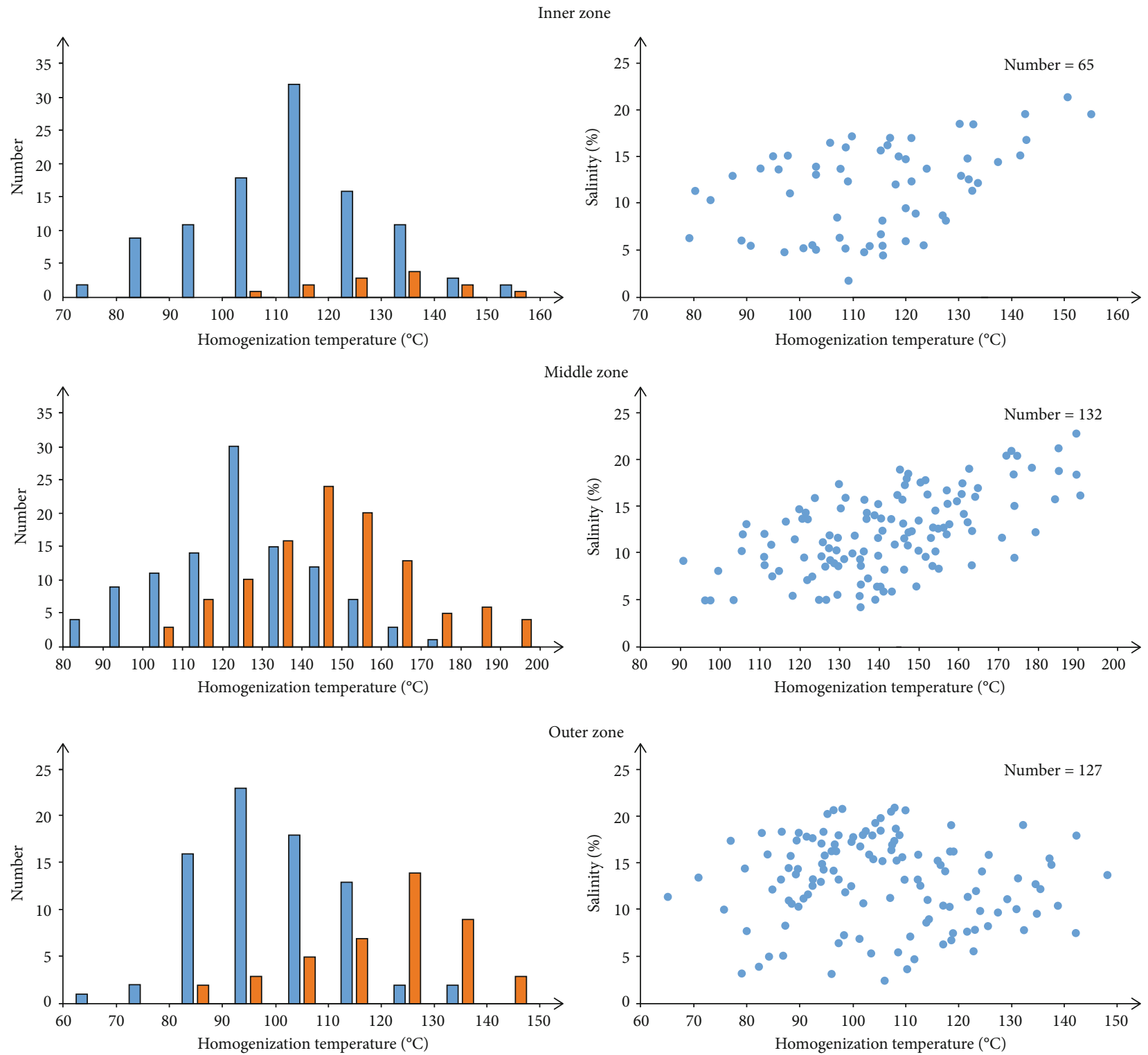

$\square$ Early phase

$\square$ Later phase

Figure 6: Homogenization temperature and salinity distribution characteristics in the Linxing area.

$700 \mathrm{~m}$ to $1600 \mathrm{~m}$ (Figure 7 ), higher than that in the southwestern part of the basin, which is consistent with the strong tectonic uplift in the northeastern part of the basin since the Late Cretaceous. The denuded thickness decreases annularly from Zijinshan magmatic pluton to its surroundings, which can be attributed to the uplift of strata around Zijinshan caused by magmatic emplacement and volcanic eruption, making it more vulnerable to be denuded.

Based on data such as denuded thickness and drilling lithology, the Sweeney and Burnham [69] EASY\% Ro model in PetroMod 1D software was used to simulate the thermal evolution of multiple wells. The specific method is to take the Ro and the homogenization temperature of fluid inclusions as the standard values, and to continuously adjust the paleo-heat flow until the simulated values of Ro and stratum temperature match the standard values, a reliable thermal evolution history can be obtained. Taking LX-4 well as an example, the Ro in Benxi Formation of LX-4 well is $2.32 \%$, and the maximum homogenization temperature of aqueous inclusions in the Taiyuan Formation is about $195^{\circ} \mathrm{C}$. With the above data as standard values, the related data in LX-4 well are simulated as shown in Figure 8, which matches the standard values, and the sedimentary burial-thermal evolution can be obtained (Figure 9).

Different burial-thermal evolution often represents different hydrocarbon accumulation characteristics. Based on the above studies, the study area can be divided into 3 areas: the inner-magma baking area, the middle-anomal thermal area, and the outer-normal thermal area (Figure 10). The inner-magma baking area is the area where was baked by the Zijinshan magmatic pluton. The highest geothermal temperature experienced is generally greater than $200^{\circ} \mathrm{C}$ 


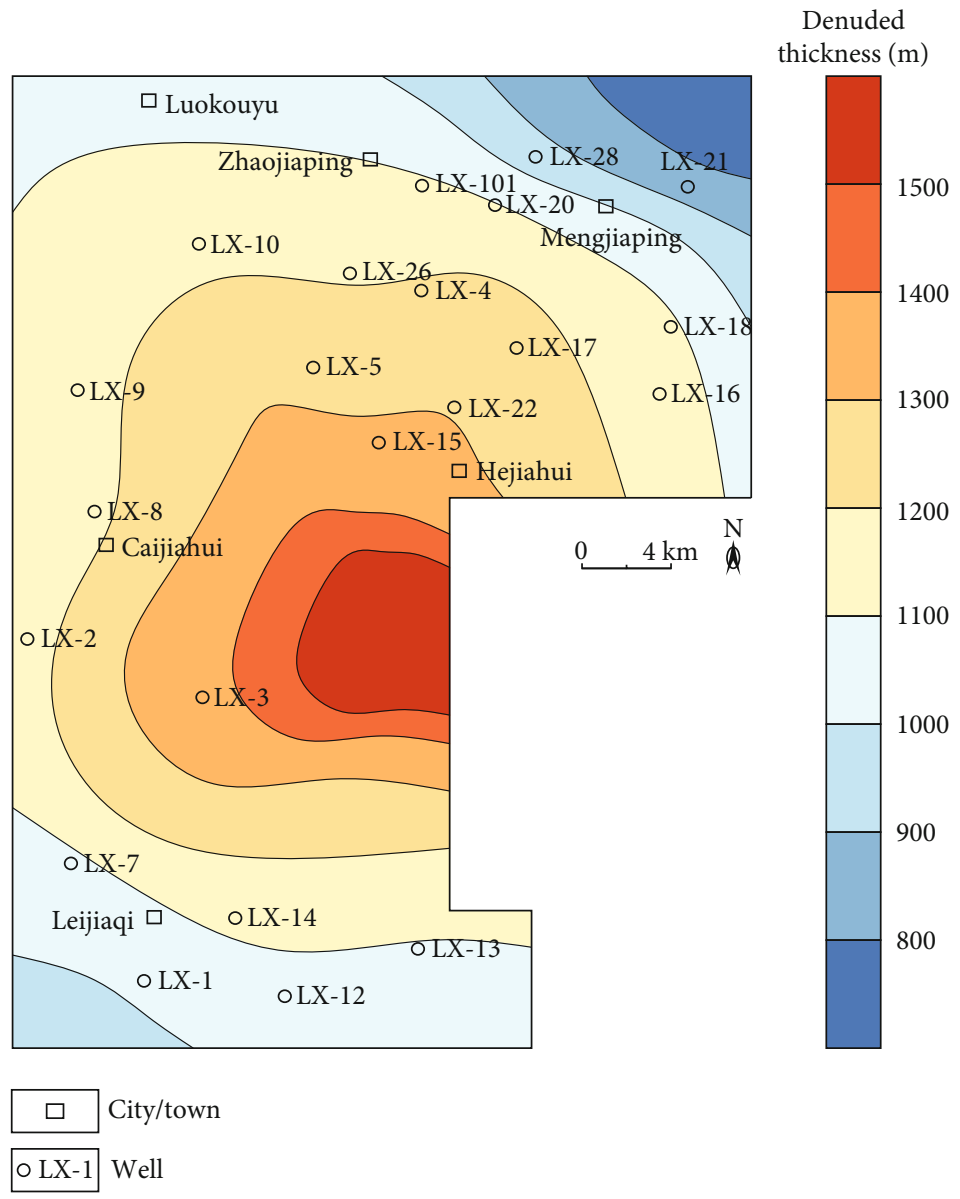

Figure 7: Contour map of denuded thickness since the Late Cretaceous in the Linxing area.

and is very close to the pluton, which was strongly influenced by its uplift (Figure S4). The middle-anomal thermal area refers to the area where the highest temperature experienced is higher $\left(180^{\circ} \mathrm{C}-200^{\circ} \mathrm{C}\right)$ and was affected by a certain degree of uplift caused by the Zijinshan magmatic pluton. The outer-normal thermal area refers to the area where the stratum temperature was weakly affected by the Zijinshan magmatic pluton (generally not exceeding $180^{\circ} \mathrm{C}$ ) and was less affected by the pluton uplifting effect.

4.3.2. Hydrocarbon Generation-Expulsion. PetroMod 1D software was used to simulate hydrocarbon generationexpulsion of coal source rocks in Taiyuan Formation, including LX-17 well in the inner-magma baking area, LX-4 well in the middle-anomal thermal area, and LX-101 well in the outer-normal thermal area (Figure 11). The simulation results show that the burial depth of coal source rocks in the Early Jurassic generally reached about $2100 \mathrm{~m}$, and the equivalent vitrinite reflectance $\left(\mathrm{R}_{\mathrm{eq}}\right)$ of coal in LX-4 and LX-17 wells near Zijinshan magmatic pluton was $0.57 \%$ $0.68 \%$, which had reached the hydrocarbon generation threshold. At this stage, gas generation was low, and some liquid hydrocarbons may be generated from the $\mathrm{H}$-rich exinite in the coal source rocks from $\mathrm{C}_{2} \mathrm{~b}$ to $\mathrm{P}_{1} \mathrm{~s}[70,71]$.

During the Middle Jurassic, the $\mathrm{R}_{\mathrm{eq}}$ of coal in LX-4 and LX-17 wells increased to $0.66 \%-0.80 \%$ (Figure 11). The thermal evolution of source rocks gradually entered a mature stage, and the intensity of hydrocarbon generation-expulsion increased relatively and maintained until the Late Jurassic, which is the first peak period of hydrocarbon generationexpulsion in the relevant areas. During the Late Jurassic, the $\mathrm{R}_{\mathrm{eq}}$ of coal in LX-101 well in the outer-normal thermal area reached $0.61 \%-0.63 \%$, which was in the stage of lowmaturity and reached the hydrocarbon generation threshold.

During the Early Cretaceous, source rocks reached the second peak period of hydrocarbon generation-expulsion, which is also the strongest period of hydrocarbon generation-expulsion. Under the dual influence of rapid sedimentary burial and Yanshanian thermal events in the North China Plate, the maximum burial depth could reach about $3000 \mathrm{~m}$, and the $\mathrm{R}_{\text {eq }}$ of coal in the LX-101 well could reach $1.21 \%$, reaching the degree of high maturity (Figure 11 ). Influenced by baking induced by Zijinshan magmatic pluton, $\mathrm{R}_{\mathrm{eq}}$ of coal in LX-4 and LX-17 wells could reach over $2.4 \%$, reaching the stage of over-mature, with the highest hydrocarbon generation-expulsion intensity.

\subsection{Gas Accumulation Characteristics}

4.4.1. Gas Accumulation Periods. Because the study area was greatly affected by thermal baking of Zijinshan magmatic pluton; if the unified burial-thermal evolution is used to 


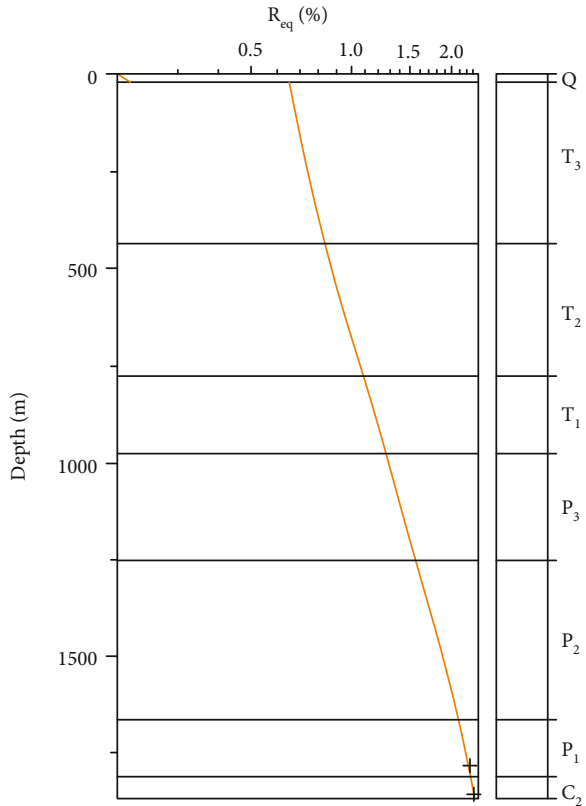

+ Measured vitrinite reflectance
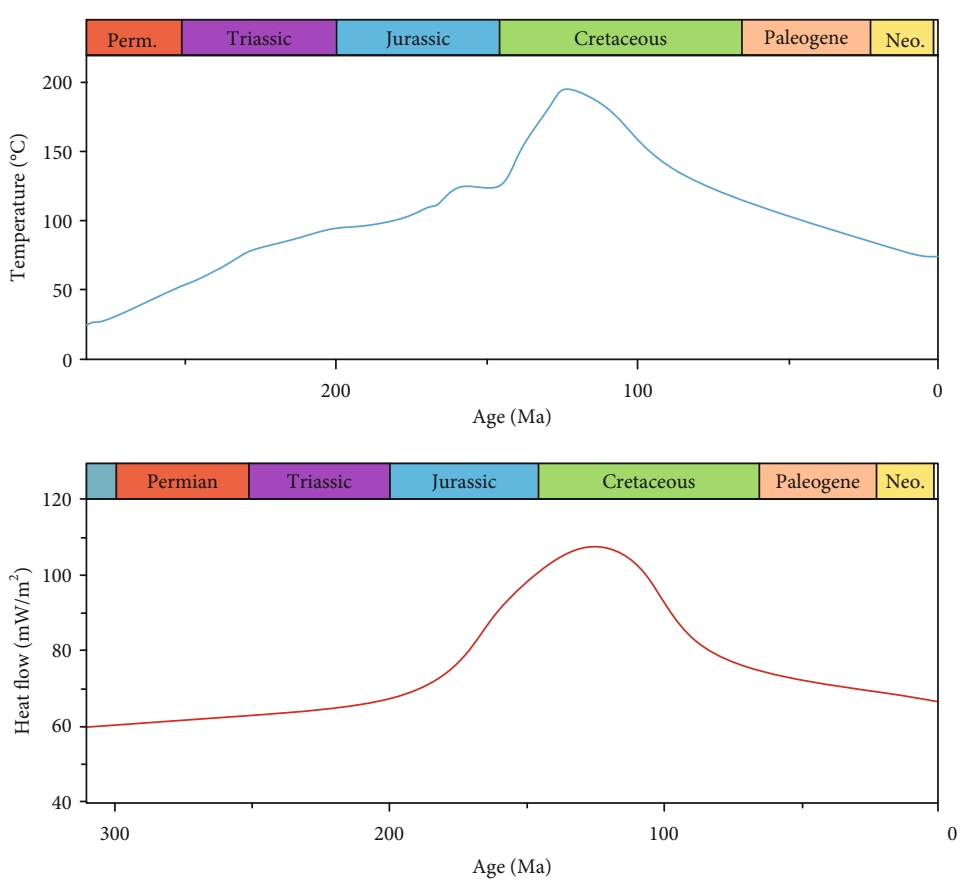

FIgURE 8: Equivalent vitrinite reflectance $\left(\mathrm{R}_{\mathrm{eq}}\right)$, formation temperature and paleo-heat flow data in restoring the thermal evolution history of LX-4 well.

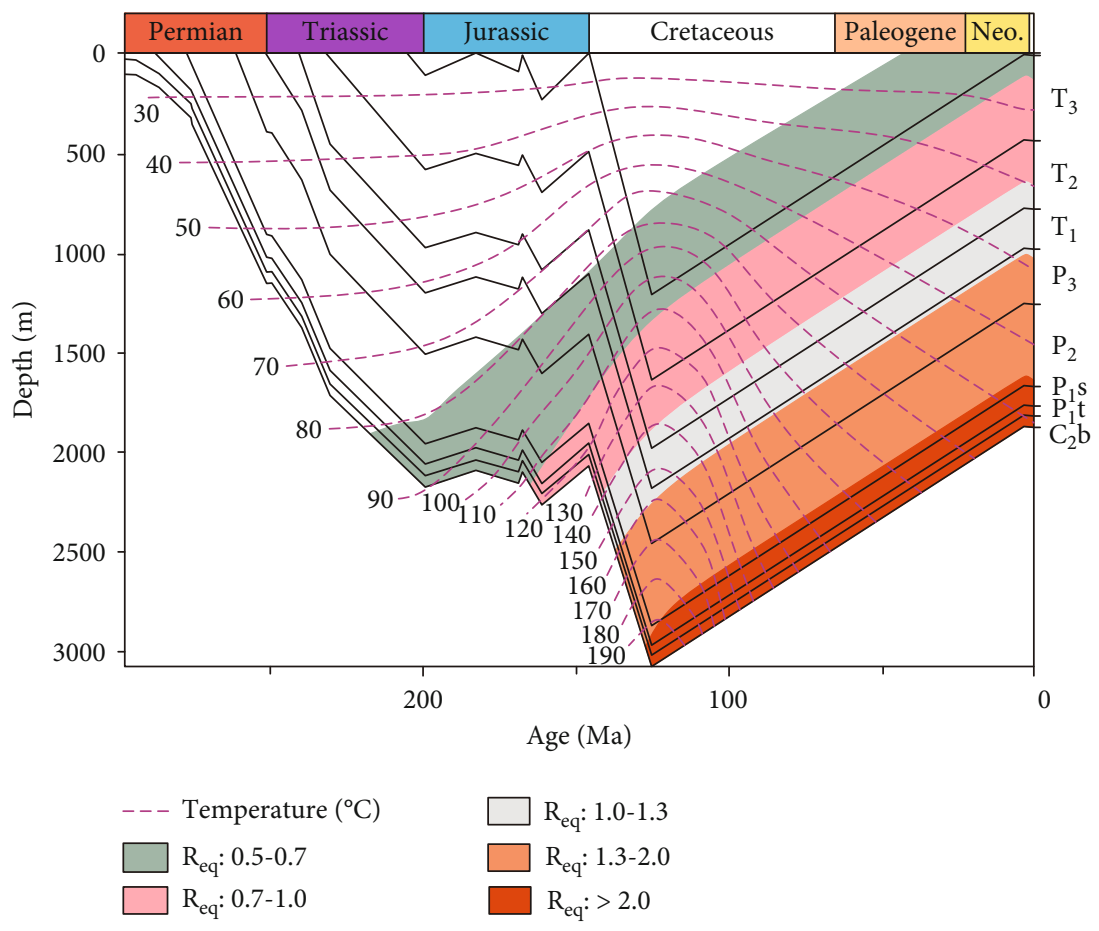

FIGURE 9: Burial-thermal evolution of LX-4 well.

analyze the gas accumulation periods, improper conclusions may be drawn. Therefore, this paper analyzed the gas accumulation periods of several wells separately.

The homogenization temperature distribution of fluid inclusions in LX-17 and LX-22 wells in the inner-magma baking area is shown in Figure 12(a). There is a homogenization temperature peak range in early fluid inclusions, while the abundance of later fluid inclusions is low and the peak value is not obvious. The temperature peak range of early fluid inclusions is $110^{\circ} \mathrm{C}-120^{\circ} \mathrm{C}$. Combining with burial- 

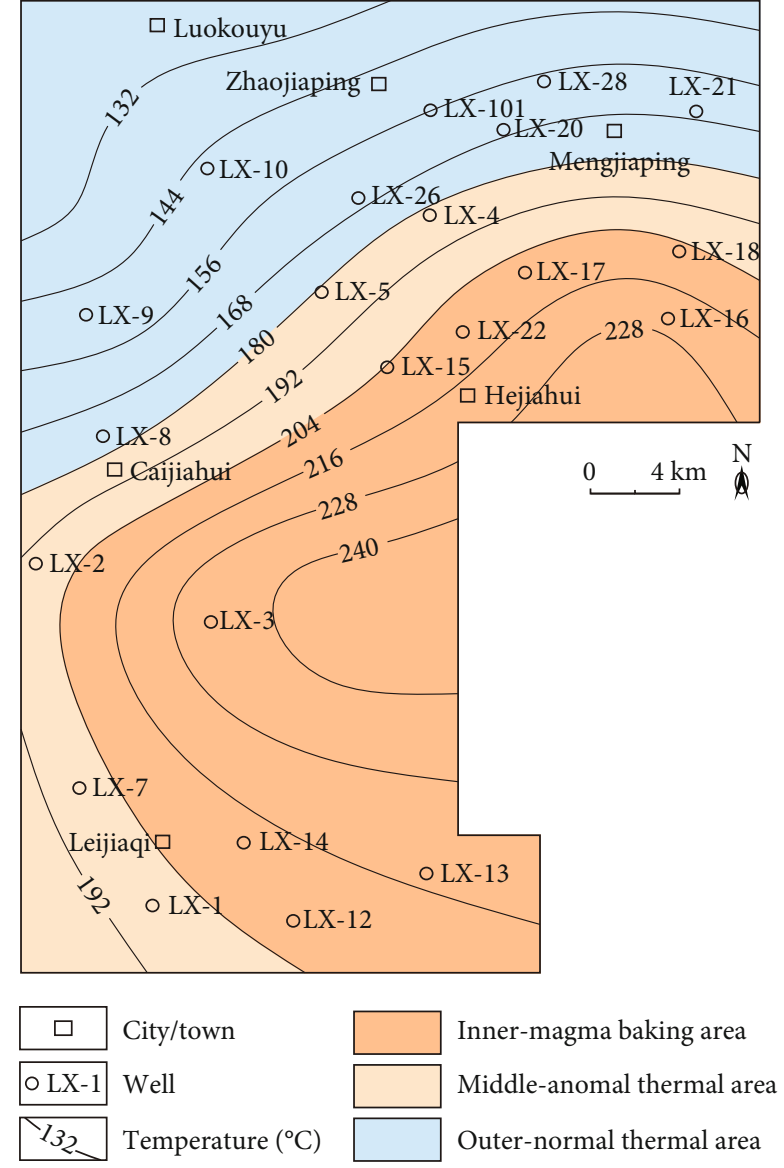

Figure 10: Regional division and geothermal contour map in the end of Early Cretaceous of Shanxi Formation in the Linxing area.

thermal evolution, it is considered that there was a major natural gas accumulation event that began in the Middle Jurassic (Figure 12(a)).

The homogenization temperature distribution of fluid inclusions in LX-1 and LX-2 wells in the middle-anomal thermal area is shown in Figure 12(b). Both early and later fluid inclusions in the two wells have homogenization temperature peak range, the temperature peak range of early fluid inclusions is $120^{\circ} \mathrm{C}-130^{\circ} \mathrm{C}$, the temperature peak range of later fluid inclusions of LX-1 well is $150^{\circ} \mathrm{C}-160^{\circ} \mathrm{C}$, and the temperature peak range of later fluid inclusions of $\mathrm{LX}-2$ well is $140^{\circ} \mathrm{C}-150^{\circ} \mathrm{C}$. Combining with burial-thermal evolution, it is believed that the first period of natural gas accumulation was the Middle-Late Jurassic, and the second period of natural gas accumulation was the Early Cretaceous (Figure 12(b)).

The homogenization temperature distribution of fluid inclusions in LX-28 and LX-101 wells in the outer-normal thermal area is shown in Figure 12(c). Both early and later fluid inclusions in the two wells have homogenization temperature peak range, the temperature peak range of early fluid inclusions is $90^{\circ} \mathrm{C}-100^{\circ} \mathrm{C}$, and the temperature peak range of later fluid inclusions of is $120^{\circ} \mathrm{C}-130^{\circ} \mathrm{C}$. Combining with burial-thermal evolution, it is believed that the first period of natural gas accumulation was the Late Jurassic, and the second period of natural gas accumulation was the Early Cretaceous (Figure 12(c)).

4.4.2. Gas Accumulation Characteristics. The vertical accumulation of natural gas in the Upper Paleozoic of the Ordos Basin is generally consistent with the characteristics of "gas accumulation in the lower reservoirs is earlier than the upper reservoirs." Natural gas fills the overlying reservoirs from the underlying coal-bearing source rocks, and the filling will inhibit the diagenesis of the filling reservoirs [72-74], resulting in a large number of low-temperature inclusions and a small number of high-temperature inclusions in the lower reservoirs. However, through the analysis of the homogenization temperature distribution characteristics, it is considered that the Linxing area has its unique vertical gas accumulation characteristics in the Ordos Basin.

There are unique gas accumulation characteristics in the inner-magma baking area and middle-anomal thermal area. Taking LX-22 well in inner-magma baking area and LX-4 well in middle-anomal thermal area as examples (Figure 13(a)), the homogenization temperature frequency distributions in the two wells in low-temperature range of relative lower formations (such as $\mathrm{P}_{1} \mathrm{t}$ in LX-4 well and $\mathrm{P}_{2} \mathrm{~s}$ in LX-22 well) are not higher than that in relative upper formations (such as $\mathrm{P}_{2} \mathrm{x}$ in LX-4 well and $\mathrm{P}_{3}$ s in LX-22 well). The data characteristics of fluid inclusions in the upper and lower formations are similar, and even the frequency of fluid inclusions in the low-temperature range of the upper formations is higher than that in the lower formations.

The outer-normal thermal area is consistent with the gas accumulation characteristics of the Ordos Basin. Taking LX21 and LX-101 wells in the outer-normal thermal area as examples, the gas accumulation consistent with the characteristics of "gas accumulation in the lower reservoirs is earlier than the upper reservoirs." The frequency distributions of homogenization temperature in two wells (Figure 13(b)) are obviously different from that in Figure 13(a). The frequency in the low-temperature range of the relative lower formations (such as $\mathrm{P}_{2} \mathrm{x}$ in LX-21 well and $\mathrm{P}_{1} \mathrm{t}$ in LX-101 well) of the two wells is higher than that in the relative upper formations (such as $\mathrm{P}_{3} \mathrm{~s}$ in LX-21 well and $\mathrm{P}_{2} \mathrm{x}$ in LX-101 well).

In case of single well contingency, taking $\mathrm{C}_{2} \mathrm{~b}, \mathrm{P}_{1} \mathrm{t}$, and $\mathrm{P}_{1} \mathrm{~s}$ as the lower formations, $\mathrm{P}_{2} \mathrm{x}, \mathrm{P}_{2} \mathrm{~s}$ and $\mathrm{P}_{3} \mathrm{~s}$ as the upper formations, the homogenization temperature distributions of fluid inclusions in the inner-magma baking area, the middle-anomal thermal area, and the outer-normal thermal area were counted, respectively (Figure 13(c)). The frequency in the low-temperature range of lower formations in the inner-magma baking area and the middle-anomal thermal area is not higher than that in upper formations. The homogenization temperature distributions of fluid inclusions in upper and lower formations are similar, and their gas accumulation periods should be similar. In the outer-normal thermal area, the frequency in the low-temperature range of the lower formations is higher than that in the upper formations, and its frequency is obviously higher in the temperature range from $80^{\circ} \mathrm{C}$ to $100^{\circ} \mathrm{C}$, which indicates that certain amounts of natural gas had charged into the reservoir when the lower formations were relatively low in temperature. 


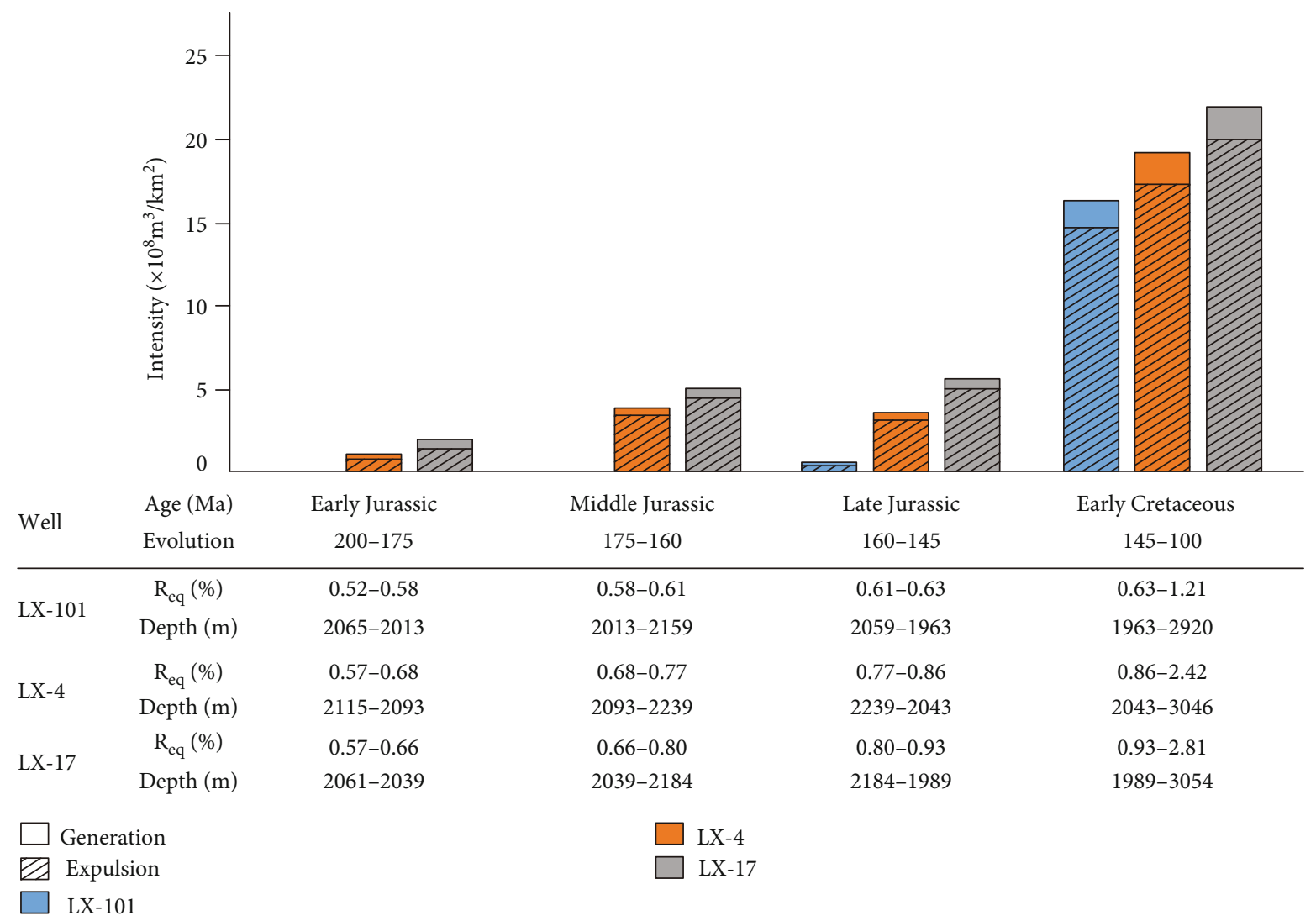

FIGURE 11: Histogram of hydrocarbon generation-expulsion intensity of coal source rocks in $\mathrm{P}_{1} \mathrm{t}$.

4.5. Trapping Pressure. The homogenization temperatures of fluid inclusions are generally lower than its trapping temperatures, which is more obvious for hydrocarbon inclusions. This phenomenon can be attributed to two main factors [57, 72]: (1) the homogenization temperatures are obtained under atmospheric pressure, while the trapping pressures are usually higher; (2) affected by the composition of inclusions, such as gaseous hydrocarbons. The trapping pressures of hydrocarbon inclusions and its coeval hydrocarbon-bearing aqueous inclusions in LX-17 and LX-18 wells were simulated by using PVTsim 20 software (Figure 14; Table 2). The results show that, on average, for hydrocarbon inclusions, the trapping temperature is $17.6^{\circ} \mathrm{C}$ higher than the homogenization temperature, and the trapping pressure is 6.2 $\mathrm{MPa}$ higher than the minimum trapping pressure; for hydrocarbon-bearing aqueous inclusions, the trapping temperature is $2.0^{\circ} \mathrm{C}$ higher than the homogenization temperature, and the trapping pressure is $5.8 \mathrm{MPa}$ higher than the minimum trapping pressure. Therefore, for samples without hydrocarbon inclusions, the trapping temperature can be approximately obtained by homogenization temperature of hydrocarbonbearing aqueous inclusions plus $2^{\circ} \mathrm{C}$, and the trapping pressure can be obtained by substituting the isochores equation.

Due to the lack of later fluid inclusions in four wells in the inner-magma baking area, there are not enough samples to simulate reservoir pressure evolution. To solve this problem, by fitting the trapping temperatures and pressures of known fluid inclusions in the study area, it is considered that there is a good linear relationship between them $\left(R^{2}=0.993\right)$ (Figure 15). Combining with the study of thermal evolution recovery in Section 4.3.1, the strata temperatures are substituted into the fitting relationship between trapping temperatures and pressures, and the trapping pressures can be approximately obtained. On the basis of the above research, the evolution law of reservoir pressure during the gas accumulation periods was further obtained (Figure 16).

The reservoirs in the three areas were overpressured during the natural gas accumulation periods, but the development processes are different. During the Early Jurassic, the Upper Paleozoic reservoirs in the study area were in the state of hydrostatic pressure or weak overpressure, and then, the reservoir pressure state began to differentiate.

For the inner-magma baking area (Figure 16(a)), since the Middle Jurassic, the pressure has risen from $27 \mathrm{MPa}$ to $37 \mathrm{MPa}$ with natural gas charging. Because of the alternate occurrence of multiple small-scale strata uplift and subsidence during this time, the burial depth fluctuated but did not change much, and the pressure coefficient increased obviously, from 1.2-1.3 to 1.6-1.8. During the Early Cretaceous, with the increase of hydrocarbon generation intensity of source rocks, the reservoir pressure increased sharply, reaching a maximum of about $68 \mathrm{MPa}$. Because of the rapid subsidence, the pressure coefficient increased slightly. When 

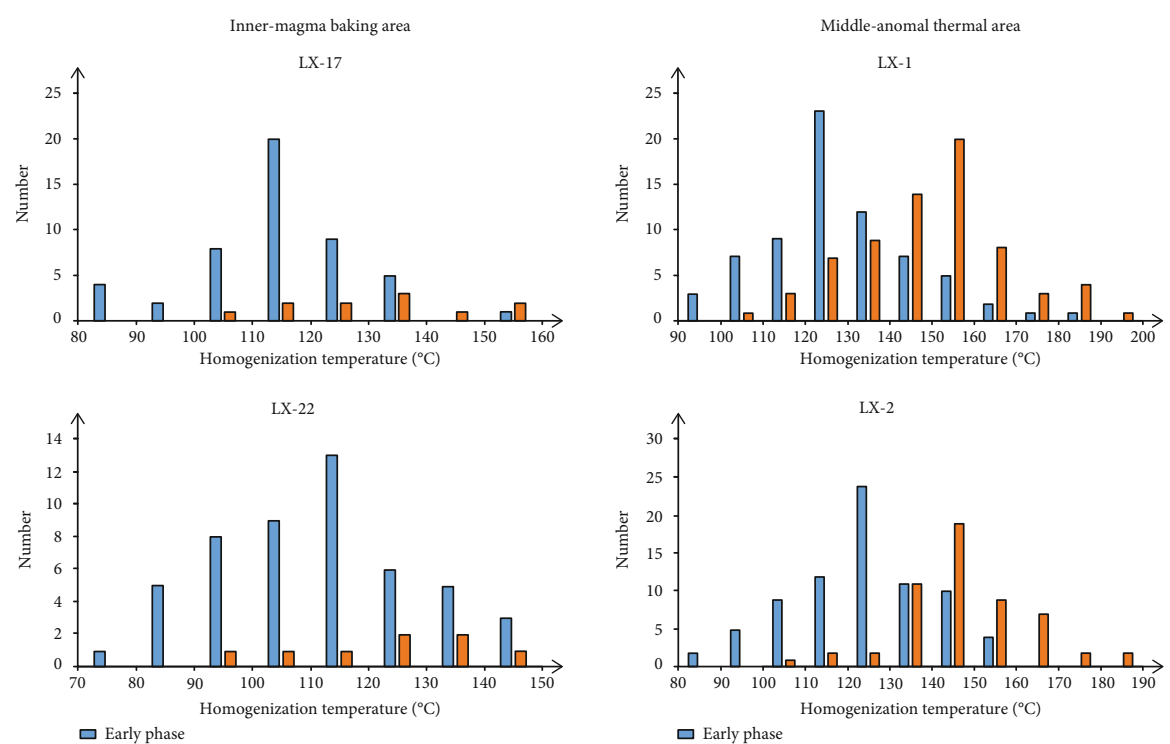

$\square$ Later phas

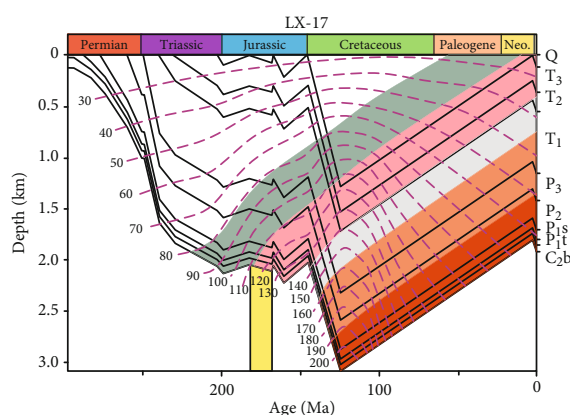

口 Later phase
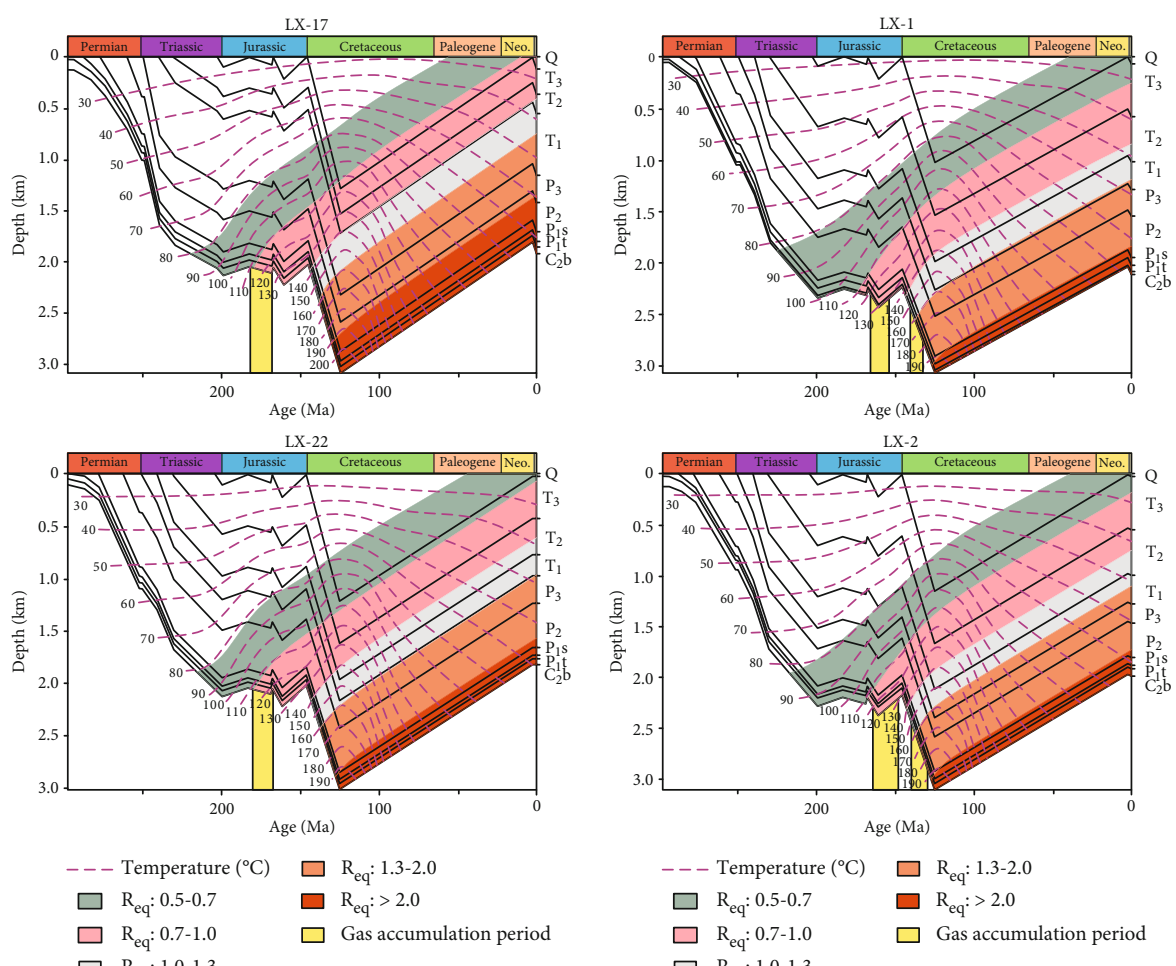

$\square \quad \mathrm{R}_{\mathrm{eq}}: 1.0-1.3$

$\square$ Gas accumulation period

(a)

$$
\begin{array}{ll}
-- \text { Temperature }\left({ }^{\circ} \mathrm{C}\right) & \square \mathrm{R}_{\text {eq }}: 1.3-2.0 \\
\square \mathrm{R}_{\mathrm{eq}}: 0.5-0.7 & \square \mathrm{R}_{\mathrm{eq}}:>2.0 \\
\square \mathrm{R}_{\mathrm{eq}}: 0.7-1.0 & \square \text { Gas accumulation period } \\
\square \quad \mathrm{R}_{\mathrm{eq}}: 1.0-1.3 &
\end{array}
$$

(b)

Figure 12: Continued. 

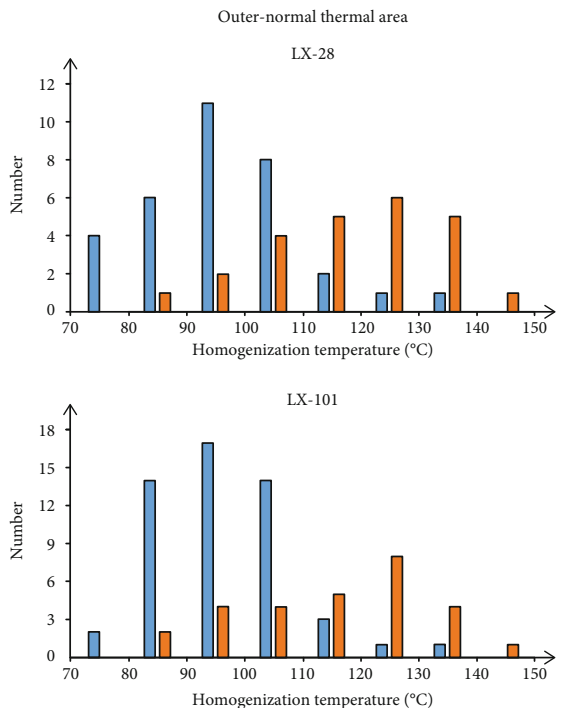

口 Early phase

$\square$ Later phase

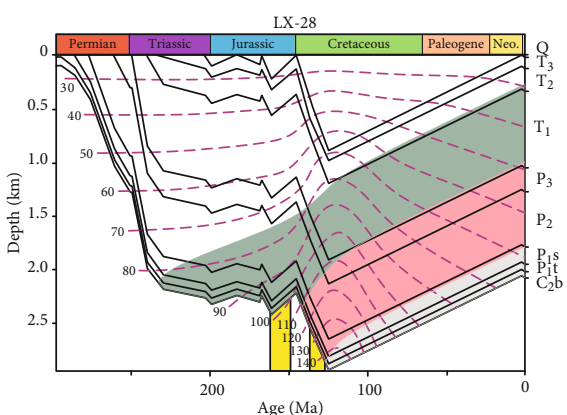

LX-101

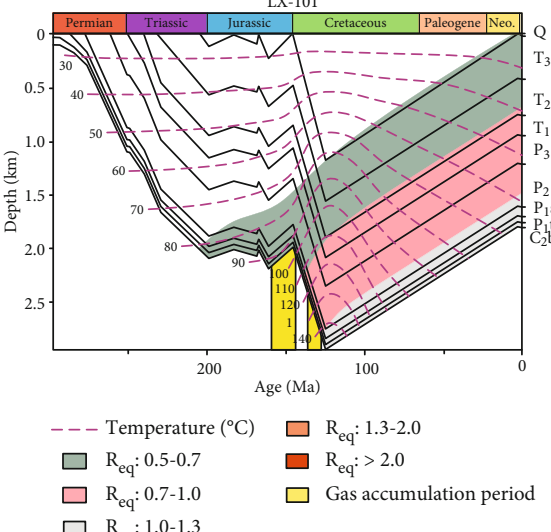

(c)

FIGURE 12: Gas accumulation periods in the Linxing area.

the subsidence reached the maximum burial depth, the pressure coefficient reached a maximum of about 2.2.

For the middle-anomal thermal area (Figure 16(b)), the reservoir pressure generally increased from $23 \mathrm{MPa}-26 \mathrm{MPa}$ to $30 \mathrm{MPa}-35 \mathrm{MPa}$ during the Middle-Late Jurassic, and the pressure coefficient was about 1.6. The development of overpressure was consistent with the first gas charging during this time. During the early Cretaceous, when the second period of natural gas accumulation occurred, the reservoir pressure increased sharply from $33 \mathrm{MPa}$ to $57 \mathrm{MPa}$. At the maximum burial depth, the pressure coefficient reached about 1.9-2.0.
For the outer-normal thermal area (Figure 16(c)), the reservoir pressure in the Middle Jurassic generally reached more than $20 \mathrm{MPa}$, and the pressure coefficient generally breaks through 1.0, which is in a weak overpressure state. During the Late Jurassic, the first period of natural gas charging occurred, and the reservoir pressure increased to $22 \mathrm{MPa}-25 \mathrm{MPa}$, and the pressure coefficient increased from 1.1 to about 1.25. During the Early Cretaceous, with the second period of natural gas charging, reservoir pressure rose sharply, up to about $40 \mathrm{MPa}$, and the pressure coefficient reached about 1.5. 

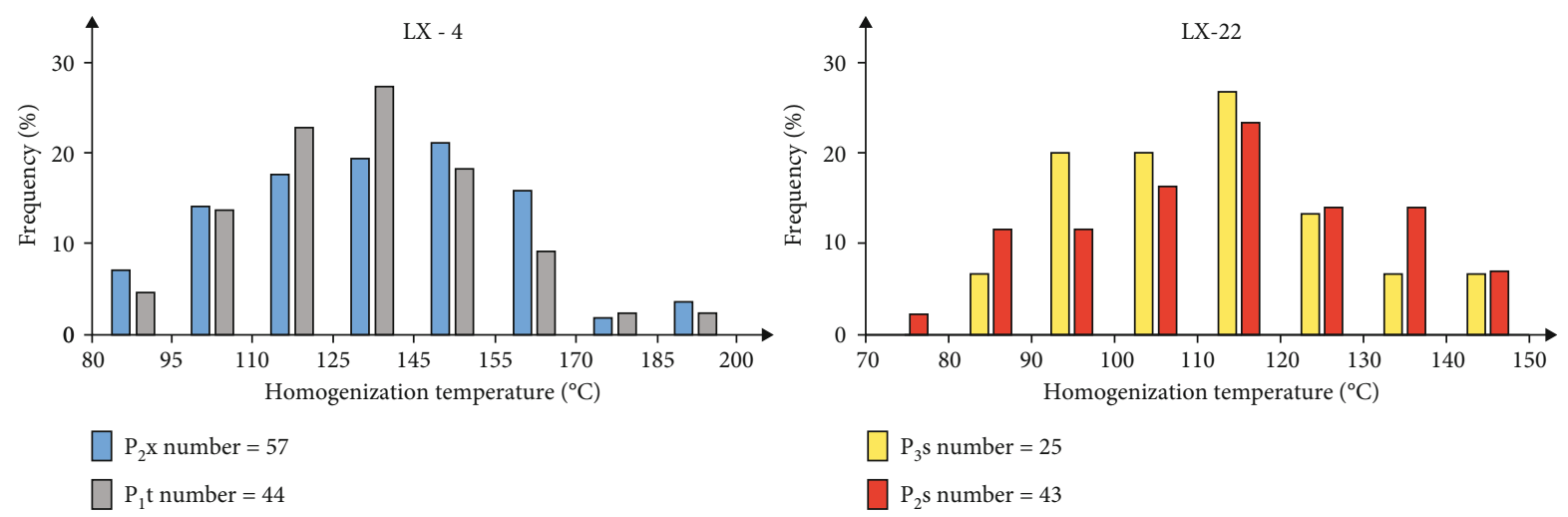

(a)
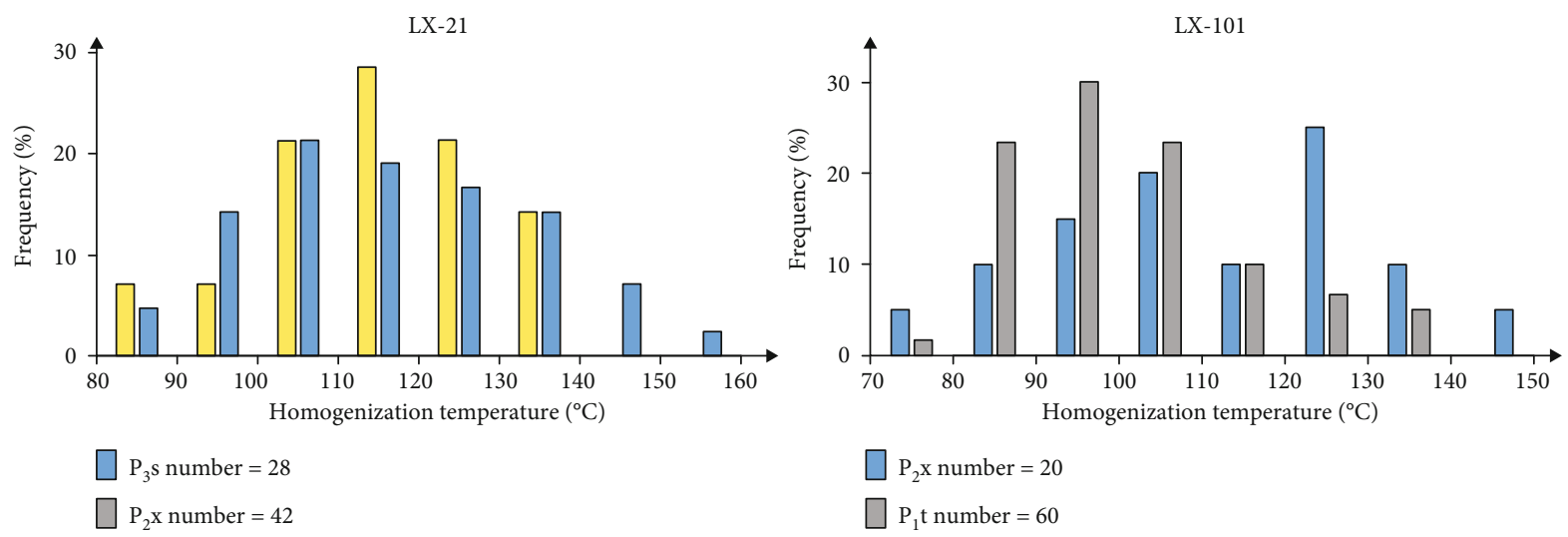

(b)
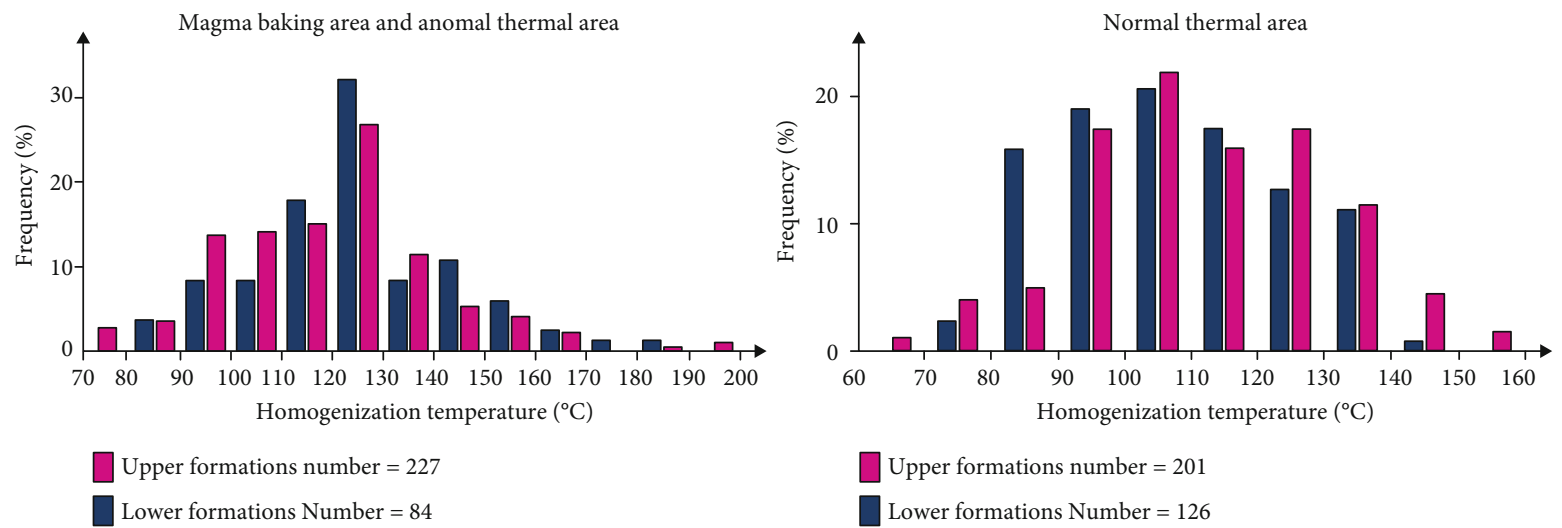

(c)

FIGURE 13: Frequency distribution of homogenization temperature for gas accumulation characteristics in the Linxing area.

4.6. Paleo-Fluid Potential. The contour maps of the paleofluid potential of the late Early Jurassic (about $175 \mathrm{Ma}$ ), the late Middle Jurassic (about $160 \mathrm{Ma}$ ), the late Late Cretaceous (about $145 \mathrm{Ma}$ ), and the middle Early Cretaceous (about $125 \mathrm{Ma}$ at the maximum burial depth) were drawn (Figure 17). The distribution characteristics of the 4 periods are similar, and the fluid potential shows the characteristics of "annular decline from the periphery of the Zijinshan magmatic pluton." The potential difference between high and low potential areas keeps increasing. Until the Early Cretaceous, due to the high thermal degree of source rocks in the area near Zijinshan magmatic pluton, the generated natural gas charged into the reservoir rapidly and massively, and the fluid potential energy rises rapidly, and the difference of fluid potential in the study area reached the maximum. The above results show that the fluid in the reservoir tended to migrated from the area around Zijinshan magmatic pluton to the low potential area.

\section{Discussion}

5.1. Influence of Zijinshan Pluton. Zijinshan magmatic pluton has a significant impact on the gas accumulation in the study area, which is manifested by regional differences in fluid 

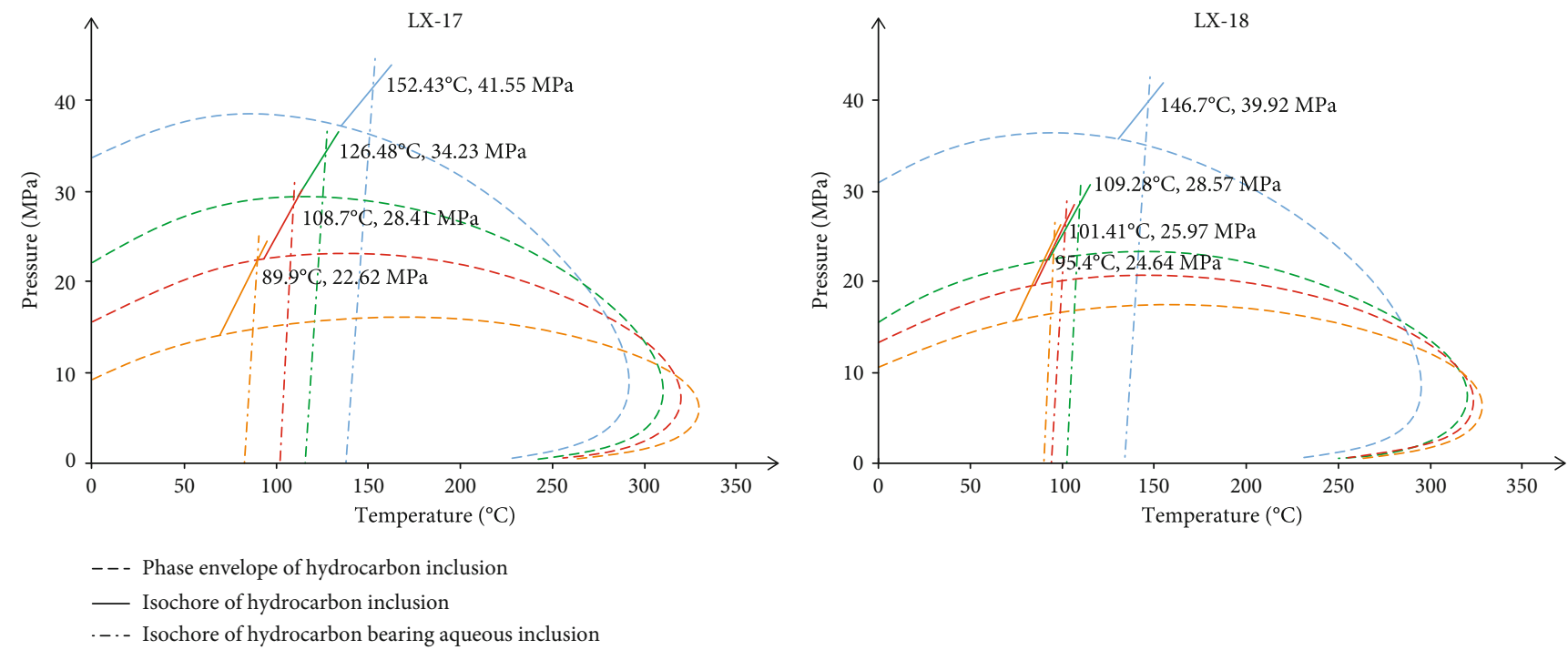

FIGURE 14: Isochores and phase envelopes for hydrocarbon inclusions in LX-17 and LX-18 wells, and isochores for its coeval hydrocarbonbearing aqueous inclusions.

TABLE 2: Trapping temperature and pressure of fluid inclusions in LX-17 and LX-18 wells.

\begin{tabular}{|c|c|c|c|c|c|c|c|}
\hline Well & $\mathrm{T}_{\mathrm{t}}\left({ }^{\circ} \mathrm{C}\right)$ & $\mathrm{P}_{\mathrm{t}}(\mathrm{MPa})$ & Type & $\mathrm{T}_{\mathrm{h}}\left({ }^{\circ} \mathrm{C}\right)$ & $\mathrm{P}_{\min }(\mathrm{MPa})$ & G/L (\%) & Isochores equation \\
\hline \multirow{8}{*}{ LX-17 } & \multirow{2}{*}{89.09} & \multirow{2}{*}{22.62} & Hydrocarbon inclusion & 69.2 & 14.04 & 8.6 & $P=0.4314 \mathrm{~T}-15.813$ \\
\hline & & & Hydrocarbon-bearing aqueous inclusion & 86.7 & 14.74 & 6.0 & $P=3.2955 \mathrm{~T}-270.98$ \\
\hline & \multirow{2}{*}{108.70} & \multirow{2}{*}{28.41} & Hydrocarbon inclusion & 92.5 & 22.46 & 18.5 & $P=0.36713 \mathrm{~T}-11.5$ \\
\hline & & & Hydrocarbon-bearing aqueous inclusion & 107.2 & 23.77 & 8.1 & $P=3.0965 \mathrm{~T}-308.17$ \\
\hline & \multirow{2}{*}{126.48} & \multirow{2}{*}{34.25} & Hydrocarbon inclusion & 110.9 & 29.31 & 31.4 & $P=0.31727 \mathrm{~T}-5.8749$ \\
\hline & & & Hydrocarbon-bearing aqueous inclusion & 124.3 & 28.27 & 9.9 & $P=2.744 \mathrm{~T}-312.81$ \\
\hline & \multirow{2}{*}{152.43} & \multirow{2}{*}{41.55} & Hydrocarbon inclusion & 134.7 & 37.14 & 57.7 & $P=0.24847 \mathrm{~T}+3.6715$ \\
\hline & & & Hydrocarbon-bearing aqueous inclusion & 150.7 & 37.34 & 12.9 & $P=2.433 \mathrm{~T}-329.31$ \\
\hline \multirow{8}{*}{ LX-18 } & \multirow{2}{*}{95.40} & \multirow{2}{*}{24.67} & Hydrocarbon inclusion & 73.7 & 15.59 & 10.1 & $P=0.4184 \mathrm{~T}-15.246$ \\
\hline & & & Hydrocarbon-bearing aqueous inclusion & 93.1 & 17.73 & 6.7 & $P=3.0245 \mathrm{~T}-263.85$ \\
\hline & \multirow{2}{*}{101.41} & \multirow{2}{*}{25.97} & Hydrocarbon inclusion & 84.7 & 19.49 & 14.5 & $P=0.38787 \mathrm{~T}-13.362$ \\
\hline & & & Hydrocarbon-bearing aqueous inclusion & 99.2 & 19.16 & 7.3 & $P=3.087 \mathrm{~T}-287.07$ \\
\hline & \multirow{2}{*}{109.28} & \multirow{2}{*}{28.57} & Hydrocarbon inclusion & 92.6 & 22.46 & 18.5 & $P=0.3662 \mathrm{~T}-11.45$ \\
\hline & & & Hydrocarbon-bearing aqueous inclusion & 107.3 & 21.97 & 8.1 & $P=3.33 \mathrm{~T}-335.34$ \\
\hline & \multirow{2}{*}{146.70} & \multirow{2}{*}{39.92} & Hydrocarbon inclusion & 130.5 & 35.67 & 51.4 & $P=0.26253 \mathrm{~T}+1.4094$ \\
\hline & & & Hydrocarbon-bearing aqueous inclusion & 145.2 & 36.28 & 12.2 & $P=2.424 \mathrm{~T}-315.68$ \\
\hline
\end{tabular}

$T_{t}$ : trapping temperature; $P_{t}$ : trapping pressure; $T_{h}$ : homogenization temperature; $P_{\text {min }}$ : minimum trapping pressure; G/L: gas-liquid ratio.

properties, hydrocarbon generation-expulsion, gas accumulation periods, vertical gas accumulation characteristics, and reservoir pressure.

The heterogeneity of fluid in gas accumulation period is mainly manifested in the difference of homogenization temperature and salinity distribution characteristics of fluid inclusions, which is supposed to be closely related to deep fluid activities triggered by Zijinshan magmatic pluton. Deep hydrothermal fluids are characterized by high temperature, high salinity, and rich in $\mathrm{CO}_{2}$, and often move along faults and fractures $[75,76]$. Because the inner and middle zones are close to the Zijinshan magmatic pluton, and there are many faults and fractures [77], the salinity of stratum water was in a relatively stable state during the interaction between surface freshwater and the upwelling of deep high salinity fluids. The salinity of fluid inclusions was mainly controlled by the increase of salinity solubility caused by the rise of strata temperatures. The interaction between strata water and surface freshwater was weak in the outer zone due to the lack of faults and fractures. The salinity of stratum water 


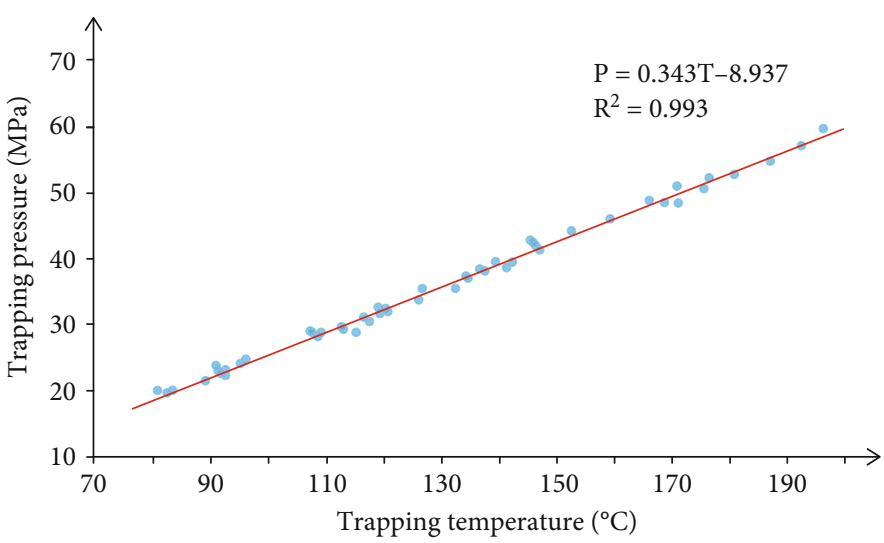

FIGURE 15: Relationship between trapping temperature and trapping pressure.

was controlled by the frequent activities of deep fluids and has a poor correlation with the temperature [78-80].

The whole gas accumulation period in the Linxing area is from the Middle Jurassic to the Early Cretaceous, but there are differences among the 3 areas. In the inner-magma baking area, there was a major natural gas accumulation event that began in the Middle Jurassic, earlier than the other two areas. There were 2 periods of gas accumulation in the middle-anomal thermal area, but the earliest time of gas accumulation is the Middle-Late Jurassic, which is later than the inner-magma baking area. There were 2 periods of gas accumulation in the outer-normal thermal area, the first occurred in the Late Jurassic.

The fundamental factor that causes the difference in the accumulation periods of the study area is the thermaltectonic effect induced by the Zijinshan magmatic pluton. The inner-magma baking area was most strongly influenced by thermal baking and uplifting, and the short uplifting events in Yanshanian period cannot offset the thermal baking. Source rocks rapidly reached the degrees of highmaturity or even over-maturity, with high gas generation intensity and short interval of episodic hydrocarbon expulsion, and long-lasting gas charging and accumulation. The microfractures in coal seams and reservoirs caused by uplift also promoted the gas charging from source rocks to sandstone reservoirs. The lack of later high-temperature inclusions in the inner-magma baking area is also due to the rapid increase of gas saturation in reservoirs, the strata water was rapidly displaced, and the formation of later inclusions was inhibited [72-74], which also reflects the high gas generation in inner-magma baking area. The middleanomal thermal area suffered a certain degree of thermal baking and uplifting, which resulted in the thermal evolution of source rocks was higher than that of the basin, and the accumulation period is later than that of the inner-magma baking area. Under the influence of Zijinshan magmatic pluton, gas accumulation in the inner-magma baking area and the middle-anomal thermal area was not a "step-by-step" process from bottom to top. A large amounts of natural gas rapidly generated by the lower source rocks quickly reached the upper reservoirs through faults and fractures associated with the pluton. The interval time between the upper and lower formations is short and the accumulation time is early.
The thermal baking and uplifting effects in the outernormal thermal area were weak, and the source rock matured slowly, and the reservoirs were filled until the Late Jurassic. Affected by "episodic hydrocarbon expulsion effect" and short-term uplift events in Yanshanian period, the first period of hydrocarbon expulsion tended to stagnate, and the maturity of source rocks increased further until the Early Cretaceous rapid subsidence stage, resulting in the second period of hydrocarbon generation-expulsion. Because of the small thermal baking and uplifting, and the natural gas accumulation in this area consistent with the characteristics of "gas accumulation in the lower reservoirs is earlier than the upper reservoirs."

The overpressure degree in the inner-magma baking area, the middle-anomal thermal area, and the outernormal thermal area decrease in turn, reflecting that thermal baking of Zijinshan magmatic pluton controlled the thermal evolution and hydrocarbon generation process of source rocks, and further affects the distribution of reservoir pressure. Besides, the pressurization caused by deep highpressure fluid and the gases released from the volatiles in the magma cannot be ignored $[81,82]$.

5.2. Natural Gas Accumulation Events. In the Linxing area, favorable source-reservoir-cap assemblages have been formed in the long process of geological and sedimentary evolution. Natural gas accumulation occurred during the Jurassic-Cretaceous, when the upper overburden rock was thick and dense, traps had been formed or were being formed in large quantities, which is a beneficial space-time matching relationship with the migration and accumulation of natural gas (Figure 18).

According to the different influence degree of the thermal-tectonic effect caused by Zijinshan magmatic pluton, natural gas reservoirs in the 3 areas were gradually formed. The hydrocarbon generation of source rocks in the innermagma baking area started the earliest, began in the Early Jurassic, and reached the first peak of hydrocarbon generation-expulsion in the Middle Jurassic. Natural gas flooded into the reservoir in large quantities. Among them, free gas migrated along the structural updip, and dissolved gas migrated to the low potential area with strata water, which accumulated and formed reservoirs in favorable traps. 

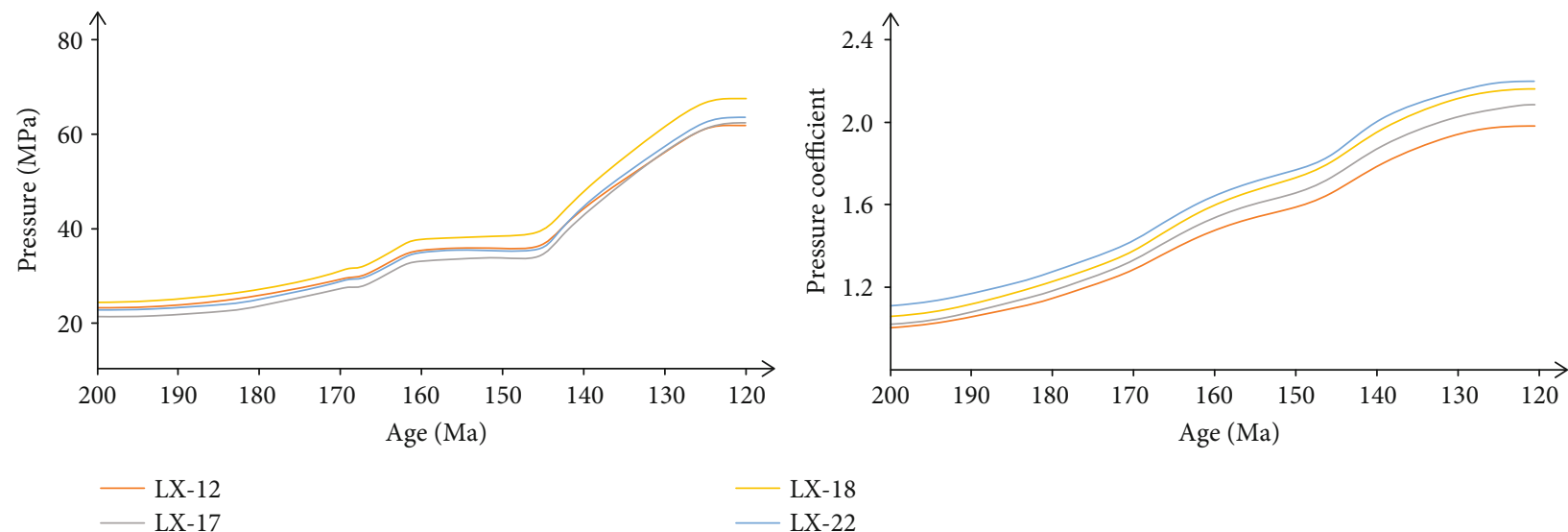

(a)
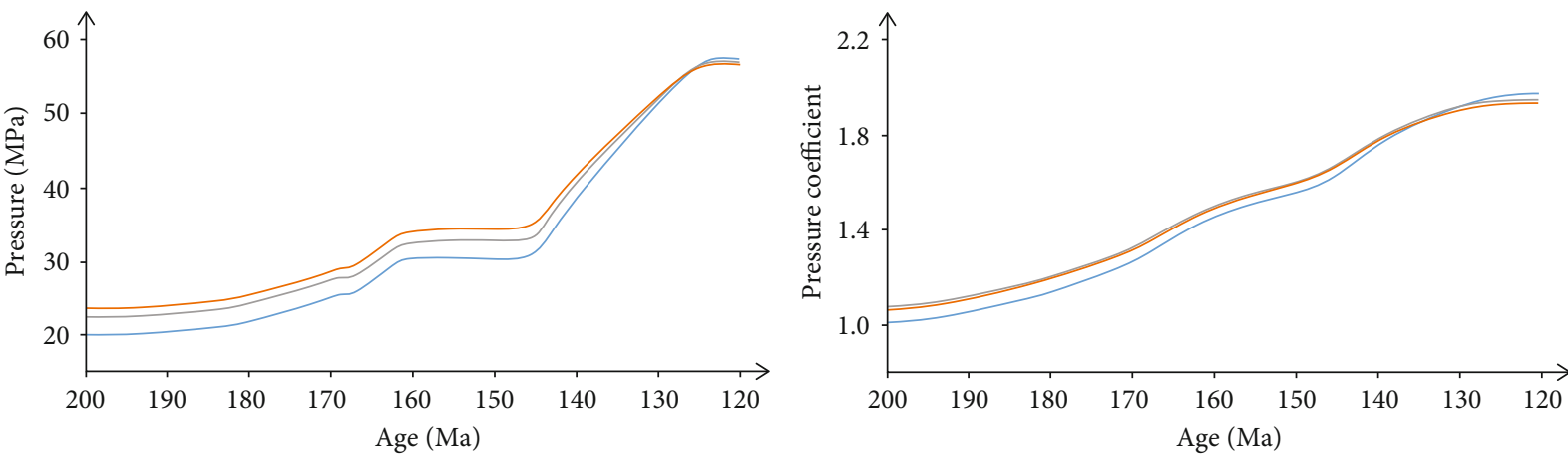

LX-1

- LX-2

- LX-4

(b)
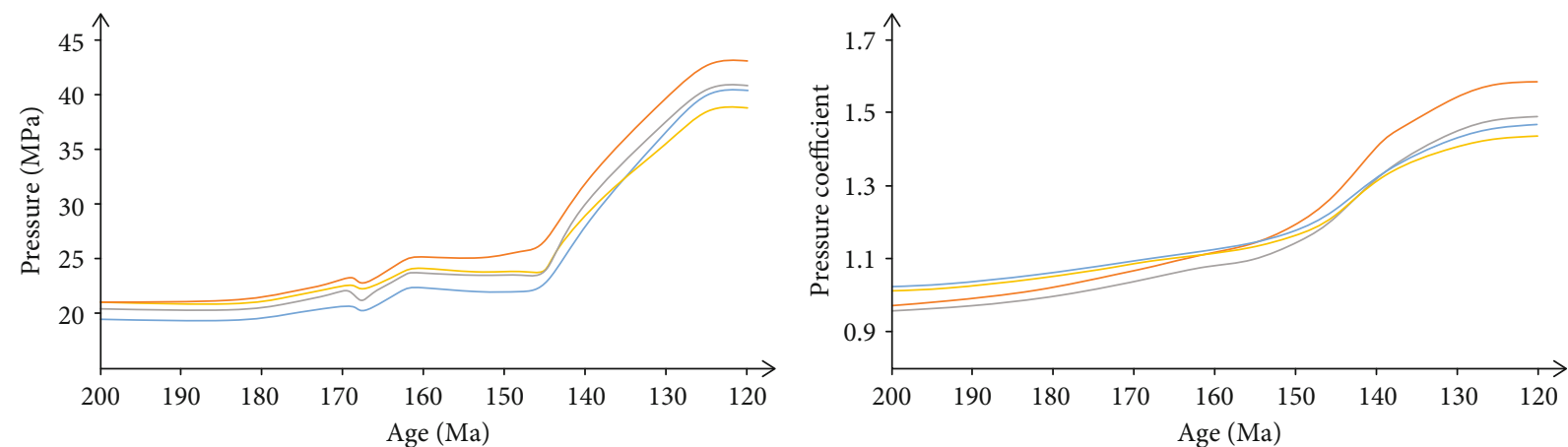

L LX-21

LX-28

LX-26

LX-101

(c)

FIGURE 16: Evolution of reservoir pressure and pressure coefficient in the Linxing area.

The source rocks in the middle-anomal thermal area also began to generate hydrocarbons in the Early Jurassic, but later than the inner-magma baking area, and the natural gas charged into the reservoirs in large quantities in the two-period accumulation of the Middle-Late Jurassic and Early Cretaceous. Source rocks in the outer-normal thermal area began to generate hydrocarbons until the Late Jurassic, and the first period of natural gas accumulation occurred. The second period of gas accumulation occurred during the Early Cretaceous.
From the Late Cretaceous to the Neogene, the Linxing area entered the period of overall uplift and gas reservoir adjustment-loss. Zijinshan magmatic pluton also rose rapidly in this period and triggered a large number of deep and large faults. Li et al. [83] calculated the gas content of sandstone reservoirs in the Linxing area according to Indonesian Formula, which shows that there exists a low gas-bearing or nongas-bearing zone around Zijinshan magmatic pluton. According to the gas reservoir profile constructed by the logging data interpretation (Figure 19), it is found that at 


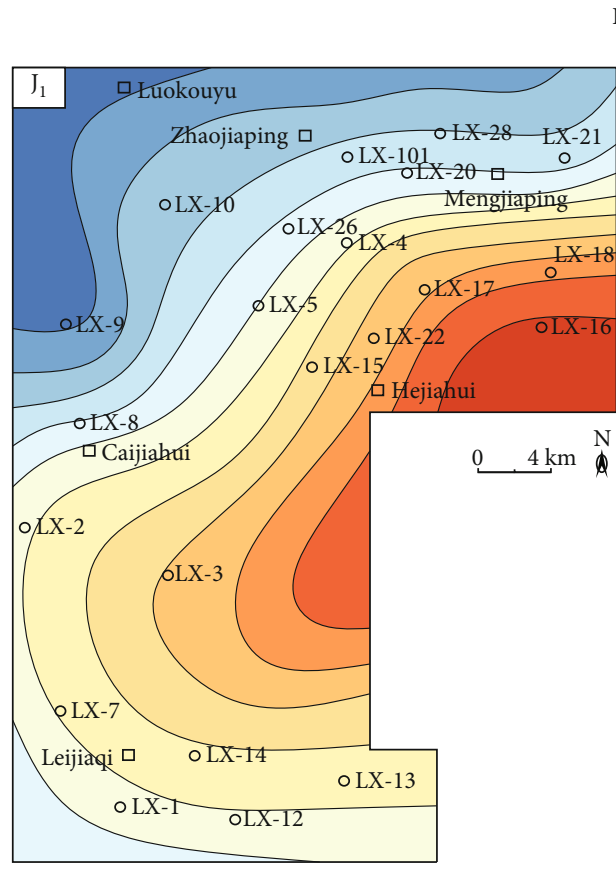

Fluid potential $\left(\mathrm{m}^{2} / \mathrm{s}^{2}\right)$
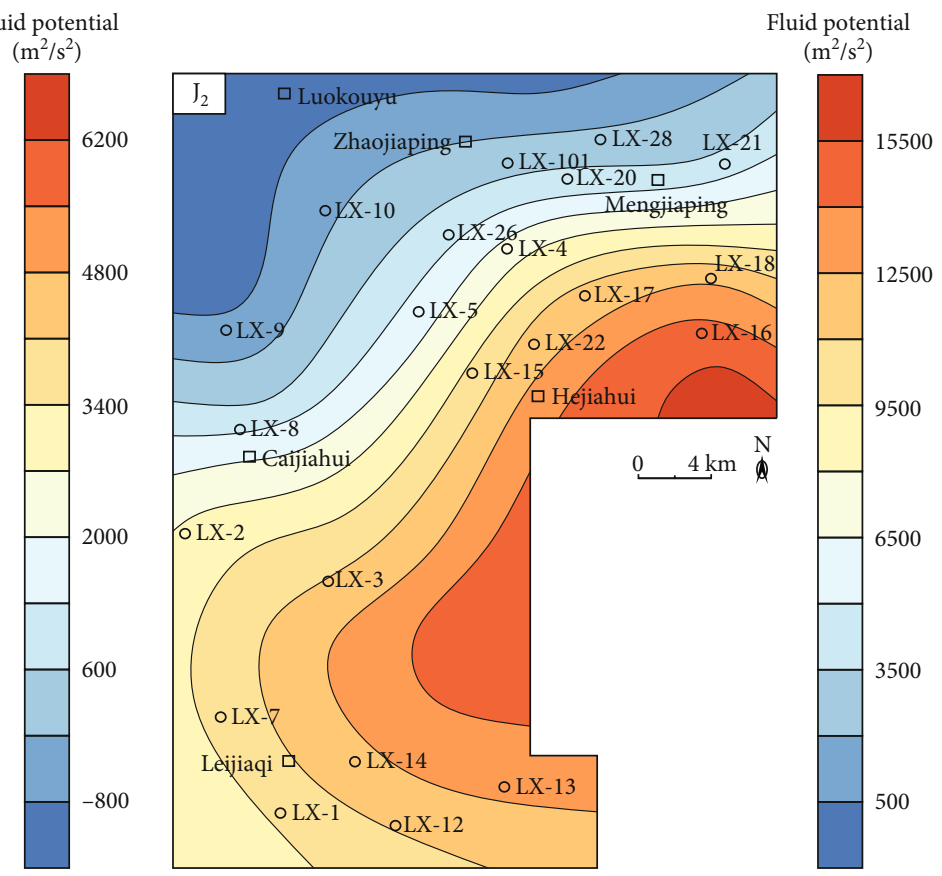

Fluid potential $\left(\mathrm{m}^{2} / \mathrm{s}^{2}\right)$
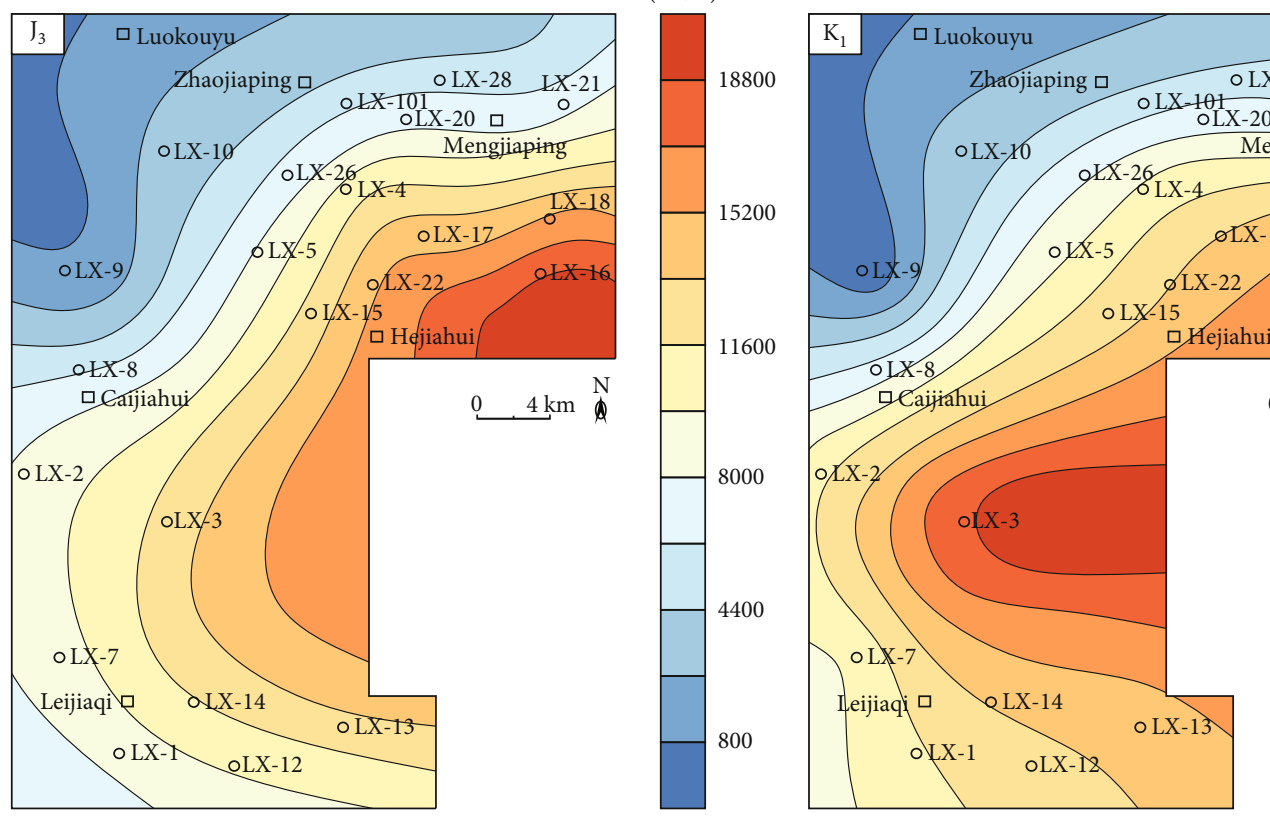

Fluid potential $\left(\mathrm{m}^{2} / \mathrm{s}^{2}\right)$

$\square$ City/town

o LX-1 Well

FIgURE 17: Evolution of fluid potential distribution in the Linxing area.

present, the reservoirs in the wells (such as LX-3 well, LX-17 well, and LX-18 well) near Zijinshan magmatic pluton are mostly water layers. It is generally believed that a large number of gas reservoirs in the inner-magma baking area were destroyed by deep and large faults, and a large number of natural gas were lost. Gas reservoirs in thermal anomaly area and normal thermal evolution area have been lost in the process of uplift, but there are fewer faults and gas reservoirs have been preserved up to now. Although the gas reservoirs in the middle-anomal thermal area and the outer-normal thermal area have a certain amount of loss during the uplift process, there are fewer faults, and the gas reservoir has been preserved until now.

5.3. Natural Gas Accumulation Model. According to the results of hydrocarbon generation-expulsion simulation, gas 


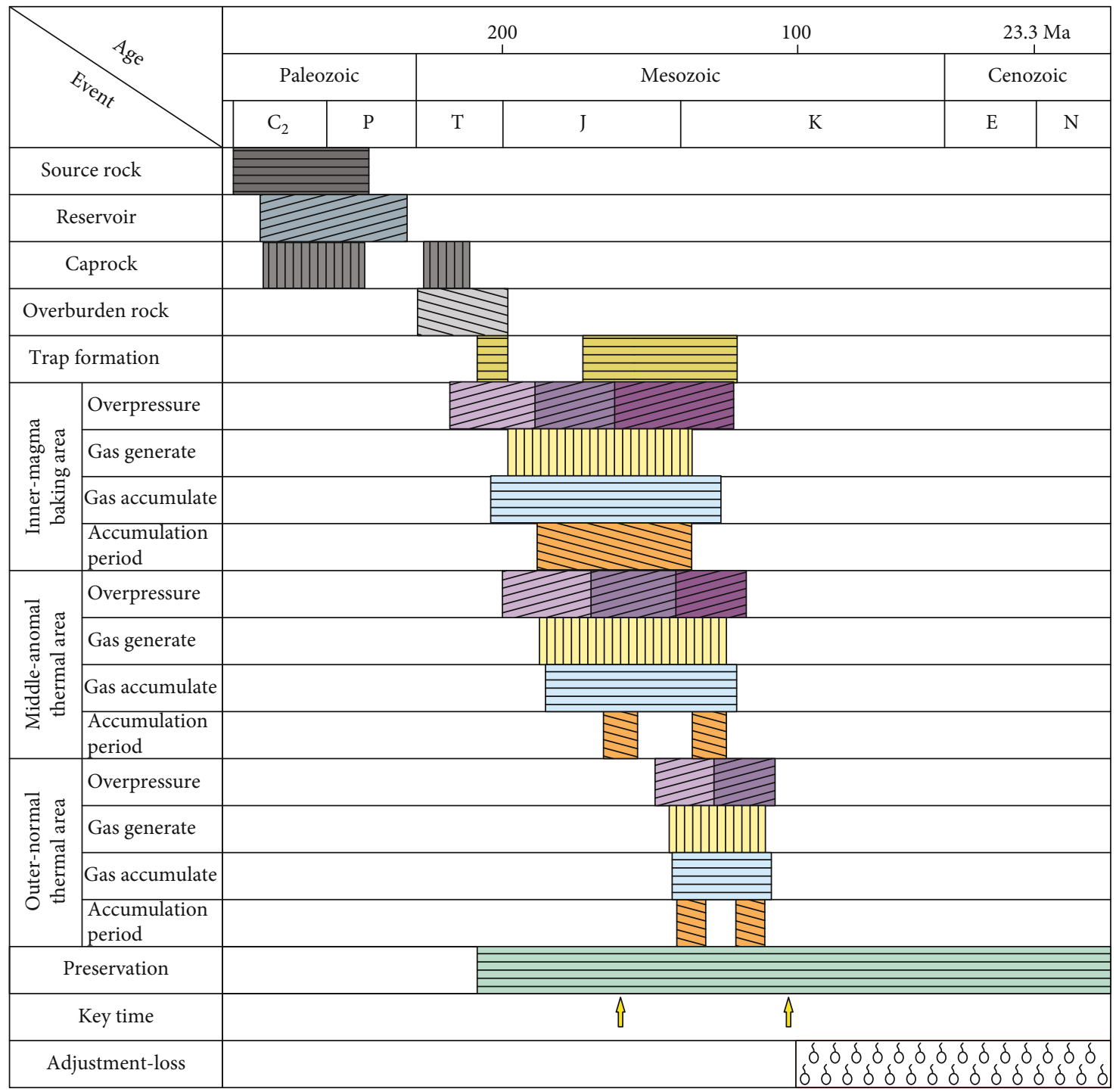

Pressure coefficient

$1.06-1.27$

$1.27-1.73$

$>1.73$

FIgURE 18: Petroleum system event in the Linxing area.

accumulation periods, reservoir pressure evolution, and fluid potential analysis, and combined with the characteristics of present gas reservoirs, it is considered that there is an accumulation model of the Upper Paleozoic tight gas reservoir in the Linxing area, which the accumulation process is affected by thermal-tectonic effect caused by the unique magmatic intrusion-the natural gas accumulation model under the control of magmatic thermal-tectonic effect.

The natural gas accumulation process in the Linxing area can be divided into 3 stages. In the first stage, the Early Jurassic, some of the source rocks near the Zijinshan magmatic pluton began to generate small amounts of natural gas and charged into the adjacent reservoirs. At this stage, the natural gas migration driving force was insufficient, and it was impossible to move laterally or vertically over long distances.

The second stage, from the Middle Jurassic to the Early Cretaceous, is the key period of gas generation, migration, and accumulation. The gas accumulation control mechanism of Zijinshan magmatic pluton is mainly reflected in its thermal baking and reservoir-transport system transformation. Thermal baking first affected the maturity evolution of source rocks in the inner-magma baking area and the 


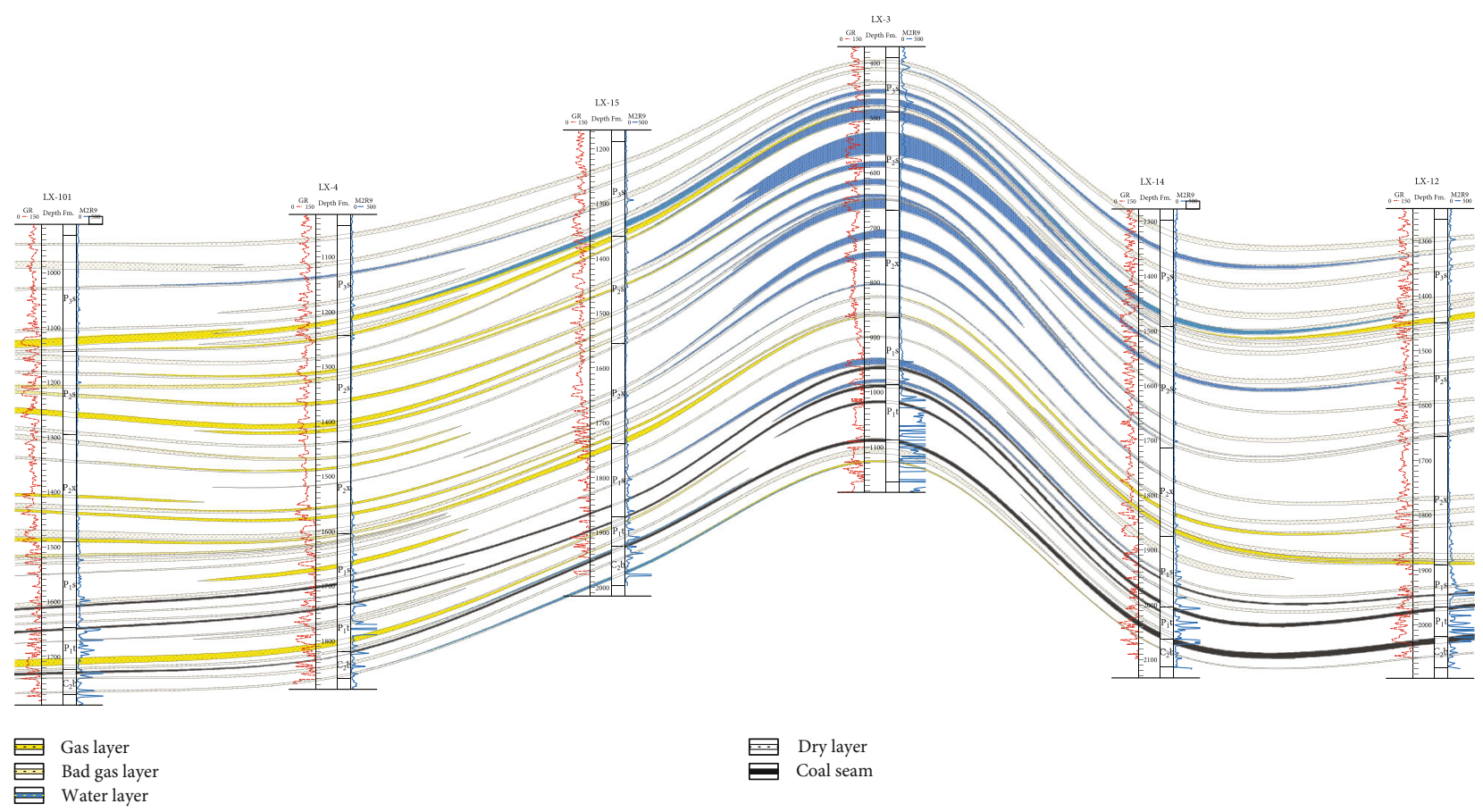

FIGURE 19: N-S gas reservoir profile in the Linxing area.

middle-anomal thermal area, which led to the large-scale hydrocarbon generation-expulsion stage in the Middle Jurassic earlier than the outer-normal thermal area. Moreover, the hydrothermal pressurization and hydrocarbon generation pressurization caused by thermal baking not only make the gaseous stratum water and natural gas migrate in a mixed state, greatly reducing the migration resistance, but also make the inner-magma baking area in a long-term high fluid potential center, which provides the driving force for natural gas migration. In the aspect of reservoir-transport system transformation, the faults and fractures caused by the intrusion of Zijinshan magmatic pluton provide a good migration channel and reservoir space for natural gas, so that natural gas can be filled to the shallow Shangshihezi Formation and Shiqianfeng Formation reservoirs (Figure 20).

In the third stage, from the end of Early Cretaceous to Neogene, the whole study area continued to uplift, and the gas accumulation control mechanism of Zijinshan magmatic pluton is mainly reflected in the gas reservoir being destroyed by faults. After severe uplift and denudation, the gas reservoir loses its overlying thick overburden rocks. Because of a large number of deep normal faults in the inner-magma baking area, a large number of natural gas is lost, and the gas reservoir was adjusted and destroyed (Figure 20). There are no deep faults in the middle-anomal thermal area and the outer-normal thermal area, and the gas reservoirs are well preserved, which are the favorable areas for natural gas exploration and development.

\section{Conclusions}

(1) The fluid heterogeneity in the Linxing area was strong during gas accumulation periods. According to the statistical analysis of homogenization tempera- ture and salinity of fluid inclusions, combined with the reconstructed burial-thermal evolution, the study area was divided into 3 areas: the inner-magma baking area, the middle-anomal thermal area, and the outer-normal thermal area

(2) Under the influence of Zijinshan magmatic intrusive tectonic-thermal event, the gas accumulation periods are different in different areas. In the inner-magma baking area, there was a major natural gas accumulation event that began in the Middle Jurassic, earlier than the other two areas. There were 2 periods of natural gas accumulation in the middle-anomal thermal area. The first period occurred from the MiddleLate Jurassic, later than the magma baking area, and the second period occurs in the Early Cretaceous. There were also 2 periods of gas accumulation in the outer-normal thermal, the first period of gas accumulation was in the Late Jurassic, and the second period occurred in the Early Cretaceous

(3) The vertical gas accumulation characteristics of natural gas show obvious regional differences. Due to the thermal-tectonic effect caused by Zijinshan magmatic pluton, natural gas accumulation in the inner-magma baking area and the middle-anomal thermal area was not a slow and gradual process from bottom to top. A large amounts of natural gas rapidly generated by the lower source rock rapidly reached the upper formation through faults and fractures caused by the intrusion of the Zijinshan magmatic pluton. The time interval between the upper and lower formations was shorter. The outer-normal thermal area was less affected by the thermal- 

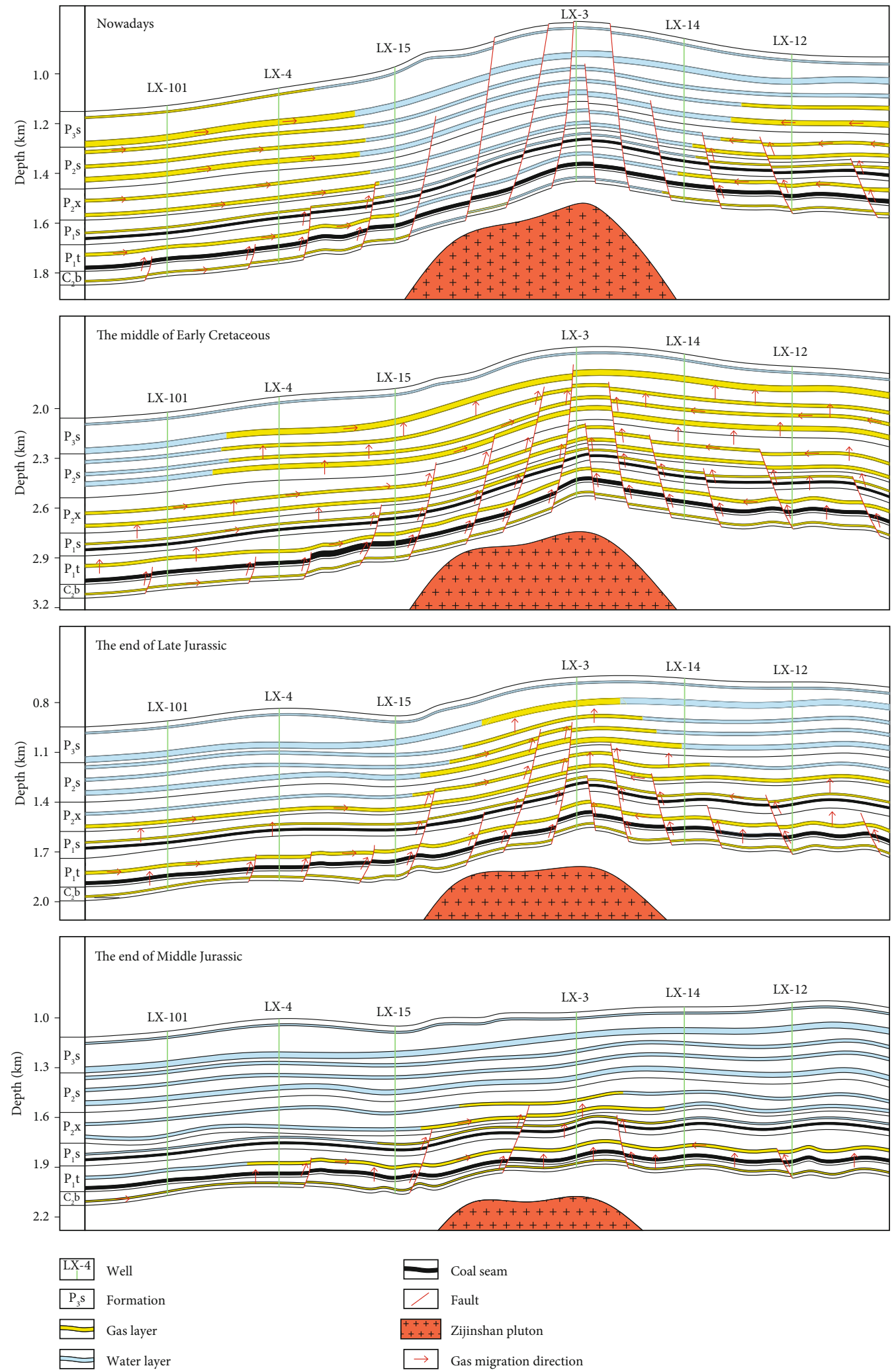

FIgURE 20: Schematic diagram of gas accumulation process and model of tight gas reservoir in the Linxing area.

tectonic effect of Zijinshan magmatic pluton, and consistent with the characteristics of "gas accumulation in the lower reservoirs is earlier than the upper reservoirs."
(4) The trapping pressure of fluid inclusions was simulated by PVTsim 20 fluid simulation software; it is shown that the Upper Paleozoic reservoirs had obvious overpressure characteristics in the gas accumulation 
periods. The period from the Middle Jurassic to the Early Cretaceous is the key period for rapid pressure accumulation, which is consistent with the period of natural gas accumulation

(5) The study on the distribution and evolution of paleo-fluid potential shows that the area near the Zijinshan magmatic pluton was the high fluid potential area during the gas accumulation periods, which indicates that natural gas and other fluids migrated from Zijinshan magmatic pluton to the surrounding area

(6) The natural gas accumulation model under the control of magmatic thermal-tectonic effect in the Linxing area was proposed. The accumulation process can be divided into 3 stages. In the first stage, during the Early Jurassic, source rocks close to the Zijinshan magmatic pluton began to generate a small amount of natural gas and charged into the adjacent reservoirs. In the second stage, the Middle Jurassic to the Early Cretaceous was the key period for gas migration and accumulation. The control mechanism of Zijinshan magmatic pluton was mainly reflected in its thermal baking and reservoir-transport system transformation. In the third stage, from the end of Early Cretaceous to Neogene, the Linxing area continued to uplift, and the formed gas reservoirs were further adjusted and destroyed due to a large number of deep faults triggered by Zijinshan magmatic pluton

\section{Data Availability}

The data used to support the findings of this study are included within the article.

\section{Conflicts of Interest}

The authors declare that there is no conflict of interest regarding the publication of this article.

\section{Acknowledgments}

This work was financially supported by the National Key Research and Development Plan (No. 2018YFB0605601) and the Project Funded by the Priority Academic Program Development of Jiangsu Higher Education Institutions (PAPD), China.

\section{Supplementary Materials}

Table S1: sedimentary facies and paleo-water depths in the northeastern Ordos Basin. Table S2: coal sample parameters for basin modeling in the Linxing area. Figure S1: evolution of paleo-heat flow in the northeastern Ordos Basin. Figure S2: photographs of cathode luminescence scan in the Linxing area. [(a) and (b) are 2 cathode luminescence photographs, the clastic composition is mainly quartz which glows blue and dark-blue light, and a few glows reddish-brown light; the quartz overgrowth does not glow with weak development, only locally developed in a few particles; calcite glows orange light. (c) and (d) are plane polarized and cathode luminescence photographs of the same sample, respectively, the quartz overgrowth is rarely developed. (e) and (f) are plane polarized and cathode luminescence photographs of the same sample, respectively, the quartz overgrowth is locally developed. (g) and (h) are plane polarized and cathode luminescence photographs of the same sample, respectively, the quartz overgrowth is relatively developed, and the broken and healed phenomenon of quartz particle can be seen. (i) and (j) are plane polarized and cathode luminescence photographs of the same sample, respectively, the quartz overgrowth is locally developed, and the broken and healed phenomenon of quartz particle can be seen. (k) and (l) are plane polarized and cathode luminescence photographs of the same sample, respectively, the quartz overgrowth is locally developed, and plagioclase glows yellow-green light.]. Figure S3: schematic diagram of the petrography of the early and later inclusions. Figure S4: $1200 \mathrm{~ms}$ seismic isochronic section in the Linxing area (cited from [14]). (Supplementary Materials)

\section{References}

[1] A. Fall, P. Eichhubl, S. P. Cumella, R. J. Bodnar, S. E. Laubach, and S. P. Becker, "Testing the basin-centered gas accumulation model using fluid inclusion observations: southern Piceance Basin, Colorado," AAPG Bulletin, vol. 96, no. 12, pp. 22972318, 2012.

[2] M. Li, W. Dou, H. Lin, Q. Zhang, and J. Jiao, "Model for tight lithologic gas accumulation in Upper Palaeozoic, east of Ordos Basin," Petroleum Exploration and Development, vol. 36, no. 1, pp. 56-61, 2009.

[3] X. Pang, Q. Meng, Z. Jiang, L. Liu, and X. Lü, "A hydrocarbon enrichment model and prediction of favorable accumulation areas in complicated superimposed basins in China," Petroleum Science, vol. 7, no. 1, pp. 10-19, 2010.

[4] T. Wang, "Gas accumulation models and characteristics of gas fields in China," Journal of Petroleum Science and Engineering, vol. 41, no. 1-3, pp. 31-43, 2004.

[5] S. A. Holditch, "Unconventional oil and gas resource development-Let's do it right," Journal of Unconventional Oil and Gas Resources, vol. 1, pp. 2-8, 2013.

[6] C. Jia, "Breakthrough and significance of unconventional oil and gas to classical petroleum geology theory," Petroleum Exploration and Development, vol. 44, no. 1, pp. 1-10, 2017.

[7] Z. Caineng, Z. Guangya, T. Shizhen et al., "Geological features, major discoveries and unconventional petroleum geology in the global petroleum exploration," Petroleum Exploration and Development, vol. 37, no. 2, pp. 129-145, 2010.

[8] Z. O. U. Caineng, Y. A. N. G. Zhi, H. E. Dongbo et al., "Theory, technology and prospects of conventional and unconventional natural gas," Petroleum Exploration and Development, vol. 45, no. 4, pp. 575-587, 2018.

[9] X. Liu, H. Zhao, X. Yan, and Y. Yani, “The geological characteristics of tight sandstone gas and exploration target evaluation in the craton basin: case study of the Upper Palaeozoic of Ordos Basin," Natural Gas Geoscience, vol. 30, no. 3, pp. 331-343, 2019.

[10] C. N. Zou, Z. Yang, S. Z. Tao et al., "Continuous hydrocarbon accumulation over a large area as a distinguishing characteristic of unconventional petroleum: the Ordos Basin, North-Central China," Earth-Science Reviews, vol. 126, pp. 358-369, 2013. 
[11] W. Ju, J. Shen, Y. Qin et al., "In-situ stress state in the Linxing region, eastern Ordos Basin, China: implications for unconventional gas exploration and production," Marine and Petroleum Geology, vol. 86, pp. 66-78, 2017.

[12] Y. Li, D. Tang, P. Wu et al., "Continuous unconventional natural gas accumulations of Carboniferous-Permian coalbearing strata in the Linxing area, northeastern Ordos basin, China," Journal of Natural Gas Science and Engineering, vol. 36, pp. 314-327, 2016.

[13] Y. G. Xie, Y. Qin, J. P. Ye, X. Z. Pan, L. J. Gao, and C. J. Duan, "Accumulation conditions of tight gas in the Upper Paleozoic of Linxing Block," Journal of China Coal Society, vol. 41, no. 1, pp. 181-191, 2016.

[14] W. Zou, H. Q. Chen, B. Yang, B. W. He, Z. H. Gui, and H. Shang, "Zijinshan pluton characteristics in Linxian, Shanxi, China, ; and its function of tight gas accumulation," Oil Geophysical Prospecting, vol. 51, pp. 120-125, 2016.

[15] W. Hu, Y. Liu, Y. Li et al., "Characteristics of Upper Paleozoic source rocks and their hydrocarbon generation and expulsion history in Linxing area, Ordos Basin," Journal of Yangtze University, vol. 15, no. 19, pp. 1-5, 2018.

[16] A. C. Aplin, S. R. Larter, M. A. Bigge, G. Macleod, R. E. Swarbrick, and D. Grunberger, "PVTX history of the North Sea's Judy oilfield," Journal of Geochemical Exploration, vol. 69, pp. 641-644, 2000.

[17] A. C. Aplin, G. Macleod, S. R. Larter, K. S. Pedersen, H. Sorensen, and T. Booth, "Combined use of Confocal Laser Scanning Microscopyand PVT simulation for estimating the composition andphysical properties of petroleum in fluid inclusions," Marine and Petroleum Geology, vol. 16, no. 2, pp. 97-110, 1999.

[18] J. R. Glasmann, R. A. Clark, S. Larter, N. A. Briedis, and P. D. Lundegard, "Diagenesis and hydrocarbon accumulation, Brent Sandstone (Jurassic), Bergen High area, North Sea," AAPG Bulletin, vol. 73, no. 11, pp. 1341-1360, 1989.

[19] R. H. Goldstein, "Fluid inclusions in sedimentary and diagenetic systems," Lithos, vol. 55, no. 1-4, pp. 159-193, 2001.

[20] R. K. Mclimans, "The application of fluid inclusions to migration of oil and diagenesis in petroleum reservoirs," Applied Geochemistry, vol. 2, no. 5-6, pp. 585-603, 1987.

[21] E. Roedder, "Volume 12: fluid inclusions," Reviews in Mineralogy, vol. 12, 1984.

[22] G. Chen, F. Yang, S. Li, H. Zhang, Y. Hu, and P. Lei, "geochronological records of oil-gas accumulations in the permian reservoirs of the northeastern ordos basin," Acta Geologica Sinica-English Edition, vol. 87, no. 6, pp. 1701-1711, 2013.

[23] L. Xinshe, Z. Lifa, and H. Yundong, "Study of gas charging in the Upper Paleozoic of Ordos Basin using fluid inclusion," Acta Petrolei Sinica, vol. 28, no. 6, p. 37, 2007.

[24] Y. Shuai, S. Zhang, J. Mi et al., "Charging time of tight gas in the Upper Paleozoic of the Ordos Basin, central China," Organic Geochemistry, vol. 64, pp. 38-46, 2013.

[25] H. Yang, F. Jinhua, X. Liu, and P. Meng, "Accumulation conditions and exploration and development of tight gas in the upper paleozoic of the ordos basin," Petroleum Exploration \& Development, vol. 39, no. 3, pp. 315-324, 2012.

[26] J. He, X. Zhang, L. Ma, H. Wu, and M. Ashraf, "Geological characteristics of unconventional gas in coal measure of Upper Paleozoic coal measures in Ordos Basin, China," Earth Sciences Research Journal, vol. 20, no. 1, pp. 1-5, 2016.
[27] J. Liu, Geochemical Characteristics of the Zijinshan Alkaline Complex in Linxing County, Taiyuan University of Technology, Shanxi Province, 2010.

[28] Shanxi Bureau of Geology and Mineral Resources, Regional Geology of Shanxi Province, Geological Publishing House, Beijing, 1989.

[29] Y. Wang, J. Cai, G. Yan, Z. Yan, and J. Song, "Geochemistry and mineral characteristics of Zijinshan alkaline complex from Linxian, Shanxi Province and its petrogenesis," Geoscience, vol. 29, no. 4, pp. 896-911, 2015.

[30] X. Yuanyuan, R. Zhanli, Q. Jiangfeng, and Z. Zhen, "Geochemistry and zircon LA-ICP MS U-Pb dating of the Zijinshan alkaline complex in the Linxian County, Shanxi Province: geological implication," Geological Review, vol. 53, no. 5, pp. 656-663, 2007.

[31] Y. Guohan, M. Baolei, and Z. Yishan, "Characteristics of REE, oxygen and strontium isotope composition for Zijinshan alkaline rocks-carbonatite complex in Shanxi Province," Acta Petrologica Sinica, vol. 3, pp. 29-36, 1988.

[32] X. K. Yang, Y. H. Yang, L. D. Ji, C. Q. Su, M. L. Zheng, and L. Zhao, "Stages and characteristics of thermal actions in eastern part of Ordos Basin,” Acta Geologica Sinica, vol. 80, no. 5, pp. 705-711, 2006.

[33] J. Ying, H. Zhang, M. Sun, Y. Tang, X. Zhou, and X. Liu, "Petrology and geochemistry of Zijinshan alkaline intrusive complex in Shanxi Province, western North China Craton: implication for magma mixing of different sources in an extensional regime," Lithos, vol. 98, no. 1-4, pp. 45-66, 2007.

[34] H. F. Zhang, G. Chen, H. P. Bao, R. S. Wang, Z. R. Ma, and T. L. Peng, "U-Pb Zircon Geochronology of the Zijinshan Alkaline Intrusive Complex, Shanxi Province, and Its Geological Significance by using LA-ICP-MS," Acta Mineralogica Sinica, vol. 31, no. 1, pp. 70-79, 2011.

[35] CNDRC (China National Development and Reform Commission), Rock thin section preparation (SY/T5913-2004), China National Development and Reform Commission, 2004.

[36] CNPC (China National Petroleum Corporation), Method for measuring homogenization temperature and salinity of sedimentary rock inclusions (SY/T6010-94), China National Petroleum Corporation, 1995.

[37] Z. Zhou, Y. Zhou, and Y. Chen, "A convenient method for obtaining vapour/liquid ratios of fluid inclusions," Geological Review, vol. 57, no. 1, pp. 147-152, 2011.

[38] Z. Xu, L. Liu, T. Wang et al., "Application of fluid inclusions to the charging process of the lacustrine tight oil reservoir in the Triassic Yanchang Formation in the Ordos Basin, China," Journal of Petroleum Science and Engineering, vol. 149, pp. 40-55, 2007.

[39] R. J. Bodnar, "Revised equation and table for determining the freezing point depression of $\mathrm{H}_{2} \mathrm{O}-\mathrm{NaCl}$ solutions," Geochimica et Cosmochimica Acta, vol. 57, no. 3, pp. 683-684, 1993.

[40] J. Y. Liu, C. S. Lin, and Y. Y. Yu, "An improved method to calculate denuded amount by sonic well logs," Experimental Petroleum Geology, vol. 22, no. 4, pp. 302-306, 2000.

[41] C. Ding, Thermal Evolution and Petroleum-Charging Times in the Northeast Area of Ordos Basin, Northwest University, 2010.

[42] R. Zhanli, Z. Zhongyuan, Z. Jun, and Y. Zhongping, "Research on Paleotemperature in the Ordos Basin," Acta Sedimentologica Sinica, vol. 12, no. 1, pp. 56-65, 1994. 
[43] Q. Yu, The Paleozoic Thermal Evolution History and Natural Gas Accumulation of the Central and Eastern Parts of Ordos Basin, Northwest University, 2012.

[44] W. A. N. G. Xue-jun, W. A. N. G. Zhi-xin, and L. I. U. Xianyang, "Restoring palaeo-depth of the Ordos Basin by using Uranium response from GR logging," Natural Gas Industry, vol. 28, no. 7, pp. 46-48, 2008.

[45] H. Yang, Q. Fu, Y. Qi, X. Zhou, N. Gong, and S. Huang, "The paleontology phase zones and its geological significance on the late Triassic Yanchang stage Palaeo-lacustrine Ordos Basin," Acta Sedimentologica Sinica, vol. 34, no. 4, pp. 688-693, 2016.

[46] J. Yang, Tectonic Evolution and Oil and Gas Distribution in the Ordos Basin, Petroleum Industry Press, Beijing, 2002.

[47] D. W. Waples, M. Suizu, and H. Kamata, "The art of maturity modeling. Part 1: alternative models and sensitivity analysis," American Association of Petroleum Geologists Bulletin, vol. 76, pp. 47-66, 1992.

[48] R. Goldstein and T. J. Reynolds, "Systematics of fluid inclusions in diagenetic minerals," SEPM SHORT COurse, vol. 31, p. 199, 1994.

[49] H. Lu, H. Fan, P. Ni, G. Ou, K. Shen, and W. Zhang, Fluid Inclusions, Science Press, Beijing, 2004.

[50] J. K. Mi, X. M. Xiao, D. H. Liu, and J. G. Shen, "Simulation for minimum trapping pressure of inclusions occurring in Upper Paleozoic sandstone reservoirs of Ordos Basin using PVTsim," Chinese Journal of Geochemistry, vol. 31, pp. 402-406, 2002.

[51] J. W. Zhang, Y. H. Zou, P. P. Li, X. Y. Fu, and W. Wang, "A new PVT simulation method for hydrocarbon-containing inclusions and its application to reconstructing paleopressure of gas reservoirs," Petroleum Geology \& Experiment, vol. 37, no. 1, pp. 102-108, 2015.

[52] M. K. Hubbert, "Entrapment of petroleum under hydrodynamic conditions," AAPG Bulletin, vol. 37, no. 8, pp. 19542026, 1953.

[53] B. Liu and G. Duan, "The density and isochoric formulae for $\mathrm{NaCl}-\mathrm{H}_{2} \mathrm{O}$ fluid inclusions (salinity $\leq 25 \mathrm{WT} \%$ ) and their applications," Acta Mineralogica Sinica, vol. 4, pp. 59-66, 1987.

[54] J. Li, G. Hu, X. Shan, and X. Luo, "Using fluid inclusion thermodynamic modeling to study paleo-fluid potential and natural gas migration and accumulation of the no. 2 member of Shanxi formation of the upper Paleozoic in Yi-Shaan slope, Ordos Basin," Earth Science-Journal of China University of Geosciences, vol. 32, no. 1, pp. 93-98, 2007.

[55] S. H. A. N. Xiuqin, L. I. Jian, H. U. Guoyi, C. Honghan, L. Xia, and G. Jiayu, "Analysis and calculation of hydrocarbon accumulation history and paleo current potential by studying fluid inclusions-an example from the Upper Paleozoic in Yulin, Ordos basin," Oil \& Gas Geology, vol. 28, no. 2, pp. 159-165, 2007.

[56] L. D. Stasiuk and L. R. Snowdon, "Fluorescence microspectrometry of synthetic and natural hydrocarbon fluid inclusions: crude oil chemistry, density and application to petroleum migration," Applied Geochemistry, vol. 12, no. 3, pp. 229-241, 1997.

[57] I. A. Munz, "Petroleum inclusions in sedimentary basins: systematics, analytical methods and applications," Lithos, vol. 55, no. 1-4, pp. 195-212, 2001.

[58] M. A. Przyjalgowski, A. G. Ryder, and M. Feely, Analysis of hydrocarbon-bearing fluid inclusions (HCFI) using timeresolved fluorescence spectroscopy, Optical Sensing and Spectroscopy, 2005.
[59] Z. C. Wang, W. Z. Zhao, X. Y. Men, H. J. Zheng, and X. Z. Li, "Control of basement fault minor-activity on gas pool formation of Upper Paleozoic, Ordos Basin," Petroleum Exploration and Development, vol. 32, no. 1, pp. 9-13, 2005.

[60] Y. Wan, G. Wang, R. Gui, C. Li, X. Yin, and J. Zhou, "Fractures of the Upper Paleozoic in Northern Shaanxi slope and its natural gas accumulation significance," Journal of Jilin University (Earth Science Edition), vol. 43, no. 1, pp. 28-38, 2013.

[61] Y. Li, H. Zhang, and Y. Tian, "Formation mechanism of coal source rocks and quartz overgrowths: an example of Shanxi Formation in eastern Ordos Basin," Geological Science and Technology Information, vol. 34, no. 6, pp. 65-69, 2015.

[62] X. Liu, M. Feng, J. Luo, and T. Lin, "Characteristics of fluid inclusions in reservoirs in the eighth member of the Shihezi Formation and the first member of the Shanxi Formation in Uxin Ju area, the Ordos Basin and their significance," Oil \& Gas Geology, vol. 31, no. 3, pp. 360-366, 2010.

[63] J. Liu, K. Liu, and L. Gui, "Fluid inclusion characteristics and hydrocarbon charge history in the upper Paleozoic, Central Ordos Basin," Journal of China University of Petroleum (Edition of Natural Science), vol. 43, no. 2, pp. 13-24, 2019.

[64] C. Luo, J. Luo, X. Luo, X. Bai, Y. Lei, and M. Cheng, "Characteristics of fluid inclusions and its application in analysis of hydrocarbon accumulation stages from the Chang 8 sandstone in the middle west area of Ordos Basin," Geological Journal of China Universities, vol. 20, pp. 623-634, 2014.

[65] K. Weng, X. Zhang, R. Li, and J. Li, "Natural gas reservoiring phases divided through method of natural gas inclusions: a case from the upper Paleozoic reservoirs in the southeastern Ordos Basin," Acta Sedimentologica Sinica, vol. 31, no. 4, pp. 693-698, 2013.

[66] C. Ruiyin, L. Xiaorong, C. Zhankun, Y. Jian, and Y. Yang, "Restoration of burial history of four periods in Ordos Basin," Acta Petrolei Sinica, vol. 27, no. 2, pp. 43-47, 2006.

[67] R. Zhanli, Z. Sheng, and G. Shengli, "Structural evolution history and its reservoir formation significance of Ordos basin," Science in China (Series D), vol. 37, pp. 23-32, 2007.

[68] R. Chen, X. Luo, Z. Chen, J. Yu, and Y. Yang, "Restoration of burial history of four periods in Ordos Basin," Acta Petrolei Sinica, vol. 27, no. 2, pp. 43-47, 2006.

[69] J. J. Sweeney and A. K. Burnham, "Evaluation of a simple model of vitrinite reflectance based on chemical kinetics (1)," AAPG Bulletin, vol. 74, no. 10, pp. 1559-1570, 1990.

[70] K. Cheng, A. Su, C. Zhao, and Z. He, "Coal-generated oil in Tuha Basin," Science in China Series D: Earth Sciences, vol. 40, no. 4, pp. 439-442, 1997.

[71] G. K. Khorasani and J. K. Michelsen, "Geological and laboratory evidence for early generation of large amounts of liquid hydrocarbons from suberinite and subereous components," Organic Geochemistry, vol. 17, no. 6, pp. 849-863, 1991.

[72] Y. Ge, Y. Chen, Y. Zhou, and Z. Zhou, "Experimental simulation of fluid inclusion response to hydrocarbon charge in carbonate reservoir," Advances in Earth Sciences, vol. 26, no. 10, pp. 1050-1056, 2011.

[73] J. Parnell, P. F. Carey, and B. Monson, "Fluid inclusion constraints on temperatures of petroleum migration from authigenic quartz in bitumen veins," Chemical Geology, vol. 129, no. 3-4, pp. 217-226, 1996.

[74] D. Yuan, Z. Zhang, and L. Zhu, "Effects of oil charge on quartz cement," Acta Petrologica Sinica, vol. 23, no. 9, pp. 2315-2320, 2007. 
[75] C. Yanjing, N. Pei, F. Hongrui et al., "Diagnostic fluid inclusions of different types hydrothermal gold deposits," Acta Petrologica Sinica, vol. 23, no. 9, pp. 2085-2108, 2007.

[76] Z. J. Jin, D. Y. Zhu, W. X. Hu, X. F. Zhang, Y. Wang, and X. B. Yan, "Geological and Geochemical Signatures of Hydrothermal Activity and Their Influence on Carbonate Reservoir Beds in the Tarim Basin," Acta Geologica Sinica, vol. 80 , no. 2, 2006.

[77] H. Zhang, Y. Feng, W. Wang, X. Chen, C. Li, and Y. Li, "Coal measures multi-target reservoir structural fracture quantitative prediction in Linxing block, eastern Ordos Basin," Coal Geology of China, vol. 29, no. 3, pp. 28-36, 2017.

[78] Q. Cao, J. Zhao, and Y. Liu, "The characteristics of fluid inclusions in Upper Paleozoic of Southeast area at Ordos Basin and their significance," Journal of Northwest University, vol. 43, no. 5, pp. 749-756, 2013.

[79] Y. Li, D. Tang, H. Xu, H. Li, and S. Tao, "Evolution of coalderived hydrocarbon based on the analysis of fluid inclusions in the Permo-carboniferous strata of Liulin area in the Ordos Basin," Geological Journal of China Universities, vol. 18, no. 3, pp. 419-426, 2012.

[80] X. Qin, R. Li, S. Xi et al., "Hydrothermal alteration and its influence on quality of the Upper Palaeozoic gas reservoirs in eastern Ordos Basin," Natural Gas Geoscience, vol. 28, no. 1, pp. 43-51, 2017.

[81] J. Qiang, M. GuoZheng, W. CongLi, and W. Li, "Thermal stimulation of hydrocarbon generation from the carboniferousPermian coal with igneous rock existing conditions," Acta Petrologica Sinica, vol. 28, no. 3, pp. 749-757, 2011.

[82] C. L. Wan, J. H. Li, W. B. Pei, and F. X. Wang, "Relationship between the temperature, pressure and geochemistry fields in the intrusive rock in sedimentary basin and oil-gas reservoirs - taking Chunxi gabbros in Dongying Sag as an example," Journal of Xi'an Shiyou University (Natural Science Edition), vol. 20, no. 1, pp. 26-29, 2005.

[83] L. I. Xia, L. I. N. Yuxiang, and Z. H. A. O. Chengjin, "Characteristics and its main controlling factors of sandstone gas content in Linxing area," Journal of Shandong University of Science and Technology (Natural Science), vol. 37, no. 1, pp. 111-118, 2018. 